\title{
Emerging treatment approaches in acute lymphoblastic and acute myeloid leukemias
}

This article was published in the following Dove Press journal:

Blood and Lymphatic Cancer:Targets and Therapy

7 March 2012

Number of times this article has been viewed

\section{Xavier Thomas \\ Hospices Civils de Lyon, Centre Hospitalier Lyon-Sud, Service d'Hématologie Clinique, Pavillon Marcel Bérard, Bât.IG, Pierre Bénite, France}

\begin{abstract}
The choice of treatment approach in acute leukemia depends on well-established prognostic factors. A number of features can predict the outcome of treatment including cytogenetics and an increasing list of molecular features. These are increasingly being used to direct postinduction therapy and support risk-adapted treatments that should achieve optimal results while minimizing nonrelapse mortality. In addition, they are also molecular targets for a new generation of small molecule inhibitors that are in early development and promise to further improve outcomes in the coming decade.
\end{abstract}

Keywords: acute myeloid leukemia, acute lymphoblastic leukemia, treatment, targeted therapy

\section{Introduction}

Acute leukemia remains one of the most challenging adult malignancies, especially with respect to therapy. Despite continuous progress in curing acute leukemia, many challenges remain including relapse among favorable-risk patients, suboptimal cure rates in older adults and dismal treatment outcome among patients who relapse. Improvements have been achieved by intensifying therapy and developing new therapeutic strategies. However, much of the improvements can be attributed to a better understanding and deployment of supportive care to carry patients through the inevitable period of severe pancytopenia caused by effective treatment. The past 10 to 15 years have witnessed substantial progress in the biologic characterization of acute leukemia, leading to the recent development of novel agents and molecular therapeutics that are being incorporated into treatment regimens.

\section{Epidemiology and pathophysiology Acute myeloid leukemia}

Acute myeloid leukemia (AML) is a malignancy that is characterized by infiltration of bone marrow (BM) by abnormal hematopoietic progenitors that disrupt normal production of erythroid, myeloid, and/or megakaryocytic cell lines. AML is a relatively rare disease with a median age of presentation in the late 60 s. In younger patients, incidence of AML is two to three per 100,000, which rises to 13 to 15 per 100,000 in the seventh and eighth decade. The French-American-British (FAB) classification, which recognized eight subtypes of AML, was based strictly on morphology and cytochemistry, ${ }^{1}$ whereas the current World Health Organization (WHO) classification, ${ }^{2}$ which also incorporates cytogenetics and disease history, classify AML 
into the following groups: (i) AML with recurrent cytogenetic abnormalities; (ii) AML with multilineage dysplasia; (iii) AML and myelodysplastic syndrome (MDS) therapy related; (iv) and AML not otherwise categorized. The outcome of treatment for adults with AML depends not only on the age and the type of postremission therapy, but also on biologic characteristics of the disease. Cytogenetics remains the most important prognostic factor. ${ }^{3,4}$ Three cytogenetic groups can be distinguished: a favorable group with core binding factor (CBF) leukemias [inv(16), $\mathrm{t}(16 ; 16)$, or $\mathrm{t}(8 ; 21)]$ and acute promyelocytic leukemia (APL) $[\mathrm{t}(15 ; 17)]$; an unfavorable group with monosomies or partial deletions of chromosome 5 and/or 7, 11q23 abnormalities, or with abnormalities involving $\geq 3$ chromosomes (complex abnormalities); and the remaining patients whose prognosis is intermediate. Long-term event-free survival in CBF leukemias is $50 \%-70 \%$, while that of intermediate-risk cytogenetics is $30 \%-50 \%$ and that of unfavorable cytogenetics is approximately $10 \%-15 \% .^{5}$ Research in defining prognostic factors has started to examine molecular markers, beginning with the P-glycoprotein transmembrane transporter proteins, which are the product of the multidrug resistance gene, $M D R-1$. Unfavorable prognosis is associated with overexpression of specific genes including: the Wilms tumor gene, $W T 1 ; ;^{6,7}$ the genes for the apoptosis regulators B-cell lymphoma protein, $B C L 2$, and BCL2-associated $\mathrm{X}$ protein, $B A X$; the brain and acute leukemia cytoplasmic gene, $B A A L C ;{ }^{8}$ the ectropic viral integration site 1 gene, $E V I 1 ;{ }^{9}$ the fms-like tyrosine kinase type 3 gene, FLT3, especially in the form of internal tandem duplication (ITD); and $K I T,{ }^{10} E R G,{ }^{11}$ and the mixed-lineage leukemia gene, $M L L .{ }^{12}$ Some mutations confer a more favorable prognosis; most notably, mutations in the gene for CCAAT enhancer binding protein- $\alpha$ (C/EBP- $\alpha), C E B P \alpha$, and nucleophosmin, NPM1. These prognostic determinants have been particularly important for patients with AML and a normal karyotype, identifying within this group two genotypes, $N P M 1^{+}$FLT3-ITD $^{-}$and CEBP $\alpha^{+}$FLT3-ITD ${ }^{-}$, which are associated with a favorable risk profile, comparable to that of CBF AML. ${ }^{13-16}$ Double mutations of $C E B P \alpha$ also confer a favorable prognosis. ${ }^{17}$ Within the group of patients with CBF leukemia, a $c$-KIT mutation identifies a subgroup with high risk of relapse. ${ }^{18}$

\section{Acute lymphoblastic leukemia}

Acute lymphoblastic leukemia (ALL), a clonal expansion of hematopoietic blasts, is a highly heterogeneous disease comprising many entities for which distinct treatment strategies are pursued. ALL is a malignant neoplasm of the lymphocyte precursor cells. The age-adjusted overall incidence of ALL is 1.5 per 100,000 population peaking between ages 2 and 5 years and again after 50 years. ${ }^{19}$ Most reports about etiologic associations remain isolated and conflicting. ALL is characterized by aberrations in proliferation and differentiation of lymphoblasts, leading to failure of normal immune response and decreased production of normal hematopoiesis responsible for anemia, thrombocytopenia, and neutropenia. Both T-cell and B-cell precursors can be involved in the malignant process. ALL is a heterogeneous disease with distinct morphologic, cytogenetics, and molecular groupings, some of which have important clinical implications. The FAB classification, which recognized three subtypes of ALL, was based strictly on morphology and cytochemistry, ${ }^{1}$ whereas the current WHO classification incorporates immunophenotyping and cytogenetics-molecular abnormalities that provide prognostic information, ${ }^{2}$ markers for therapy, targets for drug development, and pathobiologic insights (Table 1). The ambiguous expression of myeloid markers with lymphoid markers is common, especially in ALL with translocations $\mathrm{t}(9 ; 22), \mathrm{t}(4 ; 11)$, and $\mathrm{t}(12 ; 21) .{ }^{20}$ Although prognostic significance of myeloid antigens is controversial, it can help to distinguish leukemic cells from hematogones and in monitoring patients for minimal residual disease (MRD). ${ }^{21}$ Several molecular markers have been identified as key players in leukemogenesis. Activating mutations of NOTCH-1, a transmembrane receptor-encoding gene that regulates

Table I Cytogenetic and molecular abnormalities in adult ALL ${ }^{218,219}$

\begin{tabular}{|c|c|c|}
\hline Karyotype & Molecular marker & Frequency \\
\hline $\operatorname{del}(I I)(q 22)$ & ATM & $25 \%-30 \%$ \\
\hline $\mathrm{t}(9 ; 22)(q 34 ; q \mathrm{I})$ & $B C R-A B L I$ & $15 \%-25 \%$ \\
\hline$t(|4 q||-q| 3)$ & $T C R \alpha$ and $T C R \delta$ & $20 \%-25 \%$ \\
\hline $\operatorname{del}(9)(p 21-22)$ & $C D K N 2 A$ and $C D K N 2 B$ & $6 \%-30 \%$ \\
\hline $\mathrm{t}(\mathrm{I} ; \mid 4)(\mathrm{p} 32 ; \mathrm{q} \mid \mathrm{I})$ & TAL-I & $10 \%-15 \%$ \\
\hline Hyperdiploidy & - & $2 \%-15 \%$ \\
\hline+8 & - & $10 \%-12 \%$ \\
\hline $\operatorname{del}(7 p)$ & - & $5 \%-10 \%$ \\
\hline $\mathrm{t}(10 ; 14)(q 24 ; q \mid I)$ & HOXII & $5 \%-10 \%$ \\
\hline Hypodiploidy & - & $5 \%-10 \%$ \\
\hline $\operatorname{del}(I)(q 23)$ & $M L L$ & $5 \%-10 \%$ \\
\hline $\operatorname{del}(6 q)$ or $t(6 ; 12)$ & - & $5 \%$ \\
\hline $\mathrm{t}(8 ; \mid 4), \mathrm{t}(8 ; 22)$ or $\mathrm{t}(2 ; 8)$ & $c-M Y C$ & $5 \%$ \\
\hline$t(14 q 32)$ & $I G H, B C L I I B$ & $5 \%$ \\
\hline $\operatorname{del}(\mid 3)(q \mid 4)$ & $\mathrm{miR} / 5 / \mathrm{miR} / 6$ & $<5 \%$ \\
\hline $\mathrm{t}(1 ; 19)$ or $\mathrm{t}(17 ; 19)$ & TCF3-PBXI, E2A-HLF & $<5 \%$ \\
\hline $\operatorname{del}(5)(q 35)$ & HOXI IL2 & $<2 \%$ \\
\hline$t(5 ; 14)(q 35 ; q 32)$ & HOXIIL2 & $1 \%$ \\
\hline $\operatorname{del}(9)(q 32)$ & $T A L-2$ & $<1 \%$ \\
\hline $\operatorname{del}(12 p)$ or $t(12 p)$ & ETV6-RUNXI & $<1 \%$ \\
\hline Extra chromosome 9q & NUP2 / 4/ABL & $?$ \\
\hline
\end{tabular}


normal T-cell development, have been detected in the majority of T-cell ALLs. ${ }^{22}$ Loss of SMAD family member 3 (Smad3) has been identified in samples from T-lineage ALL. Epigenetic changes, including hypermethylation of tumorsuppressor genes or microRNA genes and hypomethylation of oncogenes have been identified in $80 \%$ of patients. ${ }^{23} \mathrm{ALL}$ represents less than $1 \%$ of adult cancers, while it represents $25 \%$ of all childhood cancers. Principles of chemotherapy for adult ALL are therefore based on those initially developed for children.

\section{Established and emerging therapy options \\ Acute myeloid leukemia}

\section{Established treatments}

Standard treatment of AML

The pursuit of the best chemotherapy regimen for AML continues in an attempt to improve complete remission (CR) proportions and long-term disease-free (DFS) and overall survival (OS). The modern era of treatment began in the 1970s with the introduction of anthracyclines and cytarabine as critical components that provide synergistic activity in induction regimens. In the 1980s, a schedule of daunorubicin at a dose of $45 \mathrm{mg} / \mathrm{m}^{2}$ intravenously for 3 days plus cytarabine at a dose of $100 \mathrm{mg} / \mathrm{m}^{2}$ intravenously for 7 days (' $3+7$ ' schedule) appeared more effective. ${ }^{24}$ This corresponds to the standard against which most new regimens were tested. Continuous infusion of cytarabine was more effective than single daily intravenous infusions. ${ }^{24}$ Daunorubicin given at $45 \mathrm{mg} / \mathrm{m}^{2}$ was more effective than $30 \mathrm{mg} / \mathrm{m}^{2},{ }^{25}$ while cytarabine was equally effective at $100 \mathrm{mg} / \mathrm{m}^{2}$ or $200 \mathrm{mg} / \mathrm{m}^{2} .{ }^{26}$ 6-thioguanine did not improve results when added to daunorubicin and cytarabine. ${ }^{27}$ Although not demonstrating an improved remission rate, addition of etoposide to a standard ' $3+7$ ' schedule showed improved DFS. ${ }^{28}$ Several randomized trials showed that idarubicin, ${ }^{29,30}$ aclarubicin, ${ }^{31}$ and amsacrine ${ }^{32}$ may be superior to daunorubicin in younger adults, while mitoxantrone is at least as effective as daunorubicin. ${ }^{33}$ However, these agents have been compared with daunorubicin at a dose of $45 \mathrm{mg} / \mathrm{m}^{2}$ and it is not clear that any observed improvement represents an inherent biological advantage of a particular drug rather than biological dose equivalence. Increasing the intensity of induction may be effective because achieving CR is the first condition for prolonged DFS and intensified induction therapy may affect the long-term survival even without an apparent effect on the initial response rate. The focus of research in the 1990s has therefore been on intensifying induction therapy. Several schedules have been able to deliver remission rates of $75 \%-80 \%$ in patients aged $>60$ years old. Dose escalation strategies include more days of: regularly dosed cytarabine and anthracyclines, ${ }^{34}$ high-dose cytarabine, ${ }^{35-37}$ or higher dose of daunorubicin, ${ }^{35}$ or more intensive schedules such as timed-sequential chemotherapy ${ }^{38,39}$ or double induction regimens. ${ }^{40,41}$ Overall, clinical trials with escalating intensity of therapy demonstrated no consistent advantage for remission induction, but did improve DFS. Recently, a meta-analysis of several published randomized trials demonstrated a significant benefit for using high-dose cytarabine in induction in patients younger than 60 years. ${ }^{42}$

A variety of postremission approaches have been explored. Such strategies include intensive consolidation therapy, low-dose maintenance therapy, or allogeneic or autologous stem cell transplantation (SCT). Balancing risks and benefits of different treatment approaches in accordance with the individual prognostic profile of patients is the current basic principle of treatment in AML. A number of studies have suggested that increasing the intensity of postremission therapy with doses of drugs higher than that used in standard maintenance regimens improves treatment outcome. Several studies have prospectively evaluated the role of intensive postremission consolidation with high-dose cytarabine. ${ }^{43,44}$ Four courses of cytarabine at one of the three doses were tested: $100 \mathrm{mg} / \mathrm{m}^{2} /$ day by continuous intravenous infusion for 5 days, $400 \mathrm{mg} / \mathrm{m}^{2} /$ day by continuous intravenous infusion for 5 days, and $3000 \mathrm{mg} / \mathrm{m}^{2}$ as a 3-hour intravenous infusion twice daily on days 1,3 , and $5 .{ }^{43}$ DFS was $21 \%$ in the $100 \mathrm{mg}$ group, $25 \%$ in the $400 \mathrm{mg}$ group, and $39 \%$ in the $3000 \mathrm{mg}$ group. The difference was statistically significant in patients younger than 60 years. The results were most significant in patients with favorable cytogenetics. The highand intermediate-dose regimens were of equivalent benefit in patients with intermediate-risk cytogenetics. There was no evidence that any of the three strategies were superior in patients with unfavorable cytogenetics. However, the use of high-dose cytarabine remains too toxic in the elderly. Higher doses of cytarabine $\left(18 \mathrm{~g} / \mathrm{m}^{2} /\right.$ cycle $)$ have therefore been standard for consolidation therapy in younger patients since the early 1990s and are associated with a survival benefit in CBF and intermediate-risk AMLs. ${ }^{45,46}$ This high-dose cytarabine consolidation approach has also been recommended for patients with mutations in NPMI and CEBP $\alpha$ in the absence of FLT3-ITD mutations. ${ }^{47}$ The number of courses of highdose cytarabine required for optimal postremission therapy remains uncertain. Given the evidence that intensifying postremission therapy improves the outcome of patients, studies have compared the relative benefits of intensive 
consolidation with high-dose cytarabine, autologous SCT, and allogeneic SCT. ${ }^{48-51}$ Several observations emerge from these studies: (i) due to the particular designs of these studies, a substantial proportion of patients randomized to autologous SCT failed to complete their assigned treatment; (ii) although allogeneic SCT offers the potential of graft-versus-leukemia (GvL) effect and therefore the lowest risk of relapse, higher treatment-related mortality diminishes the impact of its increased antileukemic potential; (iii) it is likely that the mortality rate associated with both autologous and allogeneic SCT will continue to decrease. Allogeneic SCT is probably still the most effective anti-AML therapy. As the donor pool expands to include more unrelated donors and umbilical cords, and as treatment-associated morbidity and mortality rates decline with improvements in human leukocyte antigen (HLA) matching, supportive cares, and management of graftversus-host disease (GvHD), it is becoming increasingly feasible for more patients with AML to undergo the procedure. All AML patients with complex cytogenetics or monosomal karyotype should be considered for allogeneic SCT. Patients with FLT3-mutated AML and those with normal cytogenetics and FLT3, CEBP $\alpha$, and NPM1 unmutated disease may be considered for allogeneic SCT. ${ }^{52}$ Reduced-intensity conditioning (RIC) regimens for allogeneic SCT that relies on the generation of a GvL effect to eradicate leukemia have been developed for older adults with AML. The treatmentrelated mortality (TRM) is approximately 30\% and outcomes among patients undergoing matched sibling donor or matched unrelated donor SCT do not appear to differ. ${ }^{53}$ It is not known which patients are most likely to benefit and whether achieving CR after induction chemotherapy alone represents sufficient reduction in the leukemia burden to realize the maximal potential of transplantation. The role of postconsolidation maintenance therapy is not clearly defined. Although not generally considered in the treatment of AML, monthly maintenance therapy has shown a potential benefit when analyzing long-term follow-up data. ${ }^{54}$

\section{Treatment of acute promyelocytic leukemia}

Several developments over the past 30 years have made acute promyelocytic leukemia (APL) the most curable of all types of AML. Addition of all-trans retinoic acid (ATRA) to chemotherapy is of clear benefit and represents the current standard approach for newly diagnosed APL. ${ }^{55,56}$ ATRA should be used together with anthracyclines during induction and probably during postremission therapy. Patients generally receive two cycles of consolidation. Anthracyclines are particularly effective in APL and have been proposed as monochemotherapy in combination with ATRA in lower risk APL. ${ }^{57}$ The development of a polymerase chain reaction (PCR) test to detect the fusion gene $P M L / R A R A$ product of the characteristic $\mathrm{t}(15 ; 17)$ provides a sensitive and highly specific means to monitor minimal residual disease. The achievement of molecular remission rates of $90 \%-99 \%$ in patients receiving at least two further cycles of anthracyclinebased chemotherapy after induction has led to the adoption of this strategy as the standard for consolidation. ${ }^{58}$ In spite of the benefit provided by ATRA-based maintenance therapy in randomized studies, the systematic use of postconsolidation therapy is still a controversial matter in patients achieving molecular remission at the end of consolidation. ${ }^{59}$ The benefit provided by ATRA-based maintenance therapy in two randomized studies ${ }^{56,60}$ has been questioned in a large study by Italian researchers. ${ }^{61}$ Two other randomized trials exploring the role of maintenance are ongoing: one comparing arsenic trioxide alone versus arsenic trioxide plus mercaptopurine and methotrexate, ${ }^{62}$ and one comparing ATRA versus the synthetic retinoid tamibarotene. Arsenic trioxide is currently regarded as the best option in the context of relapsing APL. ${ }^{63,64}$ Arsenic trioxide produces complete remission rates of $80 \%$ in relapsed APL and may be more effective than ATRA. ${ }^{65,66}$ Its role in induction and/or in postinduction therapy as first-line therapy in newly diagnosed APL is also currently being explored. ${ }^{67,68}$ In second-line therapy, the choice of transplant modality is mainly based on PCR status achieved after reinduction. After rescue with arsenic trioxide, an additional course of arsenic trioxide and ATRA as consolidation is recommended. ${ }^{59}$ This approach should be followed by molecular assessment of response by PCR of $P M L / R A R A$. Patients with persistent PCR positivity must be, when feasible, allocated to allogeneic SCT. Allogeneic SCT can also be recommended for patients with short first complete response, regardless of the molecular status after salvage therapy. For patients with prolonged first response $(>1$ year) who are in second complete molecular response, distinct strategies are available and include SCT, additional cycles of arsenic trioxide, and/or chemotherapy with or without ATRA. In patients for whom both options are feasible, autologous or allogeneic SCT are potentially curative options. ${ }^{69}$

\section{Emerging therapy options}

Despite considerable progress in the treatment of AML in recent decades, the prognosis of the majority of patients remains guarded. Only about $40 \%$ of younger adults and 
less than $10 \%$ of older patients will experience long-term survival. Current research is focusing on the identification of prognostic indicators allowing treatment stratification, the determination of new cellular targets leading to novel specific inhibitors, and the design of new therapeutic strategies combining those new agents with traditional chemotherapy. Although few new drugs have been approved for AML over the past 20 years, new strategies and new agents with diverse putative mechanisms of action are emerging and are currently entering clinical trials.

\section{Gemtuzumab ozogamicin}

Gemtuzumab ozogamicin is an immunoconjugate of an anti-CD33 antibody linked to a potent cytotoxic agent, calicheamicin. The results with gemtuzumab as a single agent for older adults as initial induction therapy have been modestly encouraging. The addition of gemtuzumab ozogamicin to induction therapy or as postconsolidation therapy in the Southwest Oncology Group (SWOG) trial, S0106, was associated with a significantly higher risk of fatal induction adverse events that led to the withdrawal of the drug from the US market. ${ }^{70}$ However, recent randomized studies have suggested that it may be associated with a higher remission rate when administered with intensive chemotherapy. ${ }^{71}$ Patients with favorable-risk cytogenetics appeared to derive a significant benefit from the addition of gemtuzumab. An OS benefit has recently been shown from a French randomized trial. ${ }^{72}$

\section{New purine analogs}

New purine analogs such as clofarabine and fludarabine exert synergistic activity with cytarabine to increase intracellular levels of the toxic metabolite cytarabine triphosphate. Fludarabine is a DNA synthesis inhibitor. Once activated, it inhibits DNA polymerase, but also ribonucleotide reductase, DNA primase, and DNA ligase I, resulting in DNA deletions and mutations. Clofarabine is an intravenous secondgeneration purine analog intentionally designed to combine the favorable properties of fludarabine and cladribine. It is active in both dividing and nondividing cells and exerts an antiproliferative effect in two important ways by both inhibiting ribonucleotide reductase and incorporating directly into DNA. In a Phase II study in patients with adverse features, clofarabine showed an overall response rate of $46 \%$ with a CR rate of $38 \% .{ }^{73}$ Combined with other agents, such as low-dose cytarabine, a higher $\mathrm{CR}$ rate was reported with an improvement in terms of OS and DFS. ${ }^{74}$

\section{FLT3 inhibitors}

The fms-like tyrosine kinase-3 (FLT3) is a receptor tyrosine kinase playing an important role in the differentiation and proliferation of hematopoietic progenitor cells. Mutations occur in about one third of patients with AML and are associated with shorter survival. ${ }^{75}$ A number of inhibitors of FLT3 kinase are currently under evaluation in AML. Midostaurin has demonstrated activity in mutated patients. ${ }^{76}$ Sorafenib, a multikinase inhibitor, has shown potent activity both as a single agent and in combination with cytotoxic agents. ${ }^{77}$ More recently, AC220, a highly specific second generation inhibitor, has been evaluated in a promising Phase I study showing approximately $50 \%$ of response in relapsing patients. ${ }^{78}$

\section{Hypomethylating agents}

The potential reversibility of epigenetic changes that contribute to the development of AML has suggested that it may be possible to reestablish normal patterns of gene expression by means of chromatin-remodeling agents. Hypermethylation of promotor regions of tumor suppressor genes has been associated with an adverse outcome in both high-risk myelodysplastic syndrome and AML. Azacytidine and 5-aza-2'-deoxycytidine can induce gene and global hypomethylation in vivo, allowing normal gene transcription to resume. ${ }^{79}$ Because of the possibility that these agents work via other mechanisms, it is also adequate to refer to them as DNA methyltransferase inhibitors based on the enzyme they inhibit. In a Phase II study involving 55 patients (median age: 74 years) treated with decitabine at a dose of $20 \mathrm{mg} / \mathrm{m}^{2}$ daily for 5 days, an overall response rate of $25 \%$ was reported with a median survival duration of 7.7 months. ${ }^{80}$ In another study, decitabine was administered at a daily dose of $20 \mathrm{mg} / \mathrm{m}^{2}$ for 10 days to 53 patients older than 60 years. ${ }^{81}$ The overall response rate was $64 \%$ including $47 \% \mathrm{CR}$ and mortality during the first 8 weeks was only $15 \%$. More recently, results from a large Phase III trial involving 485 newly diagnosed older AML patients showed a significant survival advantage (median survival: 7.7 months versus 5 months; $P=0.03$ ) and higher response rates for decitabine when compared to accepted standard therapies, without major differences in terms of safety. ${ }^{82}$

On the AZA-001 trial, 113 patients exhibiting bone marrow blast percentages between $20 \%$ and $29 \%$ are classified as AML according to the WHO criteria. ${ }^{83}$ Fifty-five patients were randomized in the azacytidine arm, while 58 received conventional care regimens. Although CR rates were similar, azacytidine was better tolerated with 
fewer severe infections and fewer days in hospitalization. The 2 -year survival was better in the azacytidine arm. However, this still remains to be proven for patients with higher blasts percentage.

Combining decitabine or azacytidine with other epigenetic modulators has been evaluated. Histone deacetylase inhibitors re-establish gene transcription either alone or following the administration of a methyltransferase inhibitor. Suberoylanilide hydroxamic acid (SAHA), valproic acid, depsipeptide, and MS-275 are examples of such novel agents.

\section{Other new agents}

Cloretazine, an alkylating agent, has been evaluated in combination with cytarabine in a randomized study. Response rate was higher for the combination, but mortality was also higher with no difference among the two groups in terms of OS and DFS. ${ }^{84}$ The proteosome inhibitor bortezomib appears to have single-agent activity in acute leukemia and has synergistic activity with histone deacetylase inhibitors. Other new agents under investigation in AML include farnesyltransferase inhibitors (tipifarnib), ${ }^{85}$ antiangiogenesis agents (bevacizumab), ${ }^{86}$ aminopeptidase inhibitors (tosedostat), ${ }^{87}$ apoptosis inhibitors (Bcl-2 antisense oligonucleotide), ${ }^{88}$ a liposome encapsulated 5:1 molar combination of cytarabine and daunorubicin (CPX-351), ${ }^{89}$ a quinolone derivative that intercalates DNA (voreloxin), ${ }^{90}$ and number of other agents that target various aspects of the leukemia cell machinery.

\section{New therapeutic strategies}

Many trials have evaluated myeloid growth factors in the supportive care setting in AML. In spite of evidence that neutropenia can be curtailed, there was no consistent evidence of improvement in disease outcome. In contrast, encouraging data have been reported recently regarding the use of growth factors in priming leukemia cells and thereby increasing sensitivity to chemotherapy. ${ }^{91,92}$ However, this remains a controversial issue for which studies showed inconsistent results.

\section{Acute lymphoblastic leukemia}

\section{Established treatments}

Because of specific treatments available for unique ALL subtypes, Philadelphia chromosome-positive $\left(\mathrm{Ph}^{+}\right)$ALL might be differentiated from $\mathrm{Ph}$-negative $\mathrm{ALL}$, and mature Burkitt B-lymphoma/leukemia from B- and T-cell precursor ALL.

\section{Standard treatment of ALL}

Most therapeutic advances in adult ALL have arisen from successful adaptation of ALL treatment in children. Results of main standard treatment programs for adult ALL are indicated in Table 2. ${ }^{93-106}$ Historically, induction therapy for adult ALL has been built around a "backbone" of vincristine and prednisone. The combination of vincristine and prednisone alone produces CR rates of approximately $35 \%$ to $65 \%$ but median remission duration of only 3 to 7 months. Intensifying induction therapy by adding an anthracycline was first shown in a randomized Cancer and Leukemia Group B (CALGB) trial to significantly increase the likelihood of achieving a $\mathrm{CR}$ from about $50 \%$ to $78 \%{ }^{107}$ These results were then confirmed by other studies. The anthracyclines used include doxorubicin, daunorubicin, and more recently idarubicin and rubidazone. Daunorubicin has been the most extensively studied because of its availability for the longest period of time, its activity, and its lower gastrointestinal mucosal toxicity. The optimal schedule for anthracycline administration is controversial. The two most commonly schedules are once weekly or daily for 3 days for each course. According to the pediatric experience, the administration over 2 or 3 days achieves a faster antileukemic effect through greater myelosuppression. Although there are no randomized studies addressing further intensification of induction therapy, almost all modern treatment regimens add L-asparaginase or cyclophosphamide to induction therapy. Asparaginase does not affect the CR rate, but probably improves leukemia-free survival and if not used during induction therapy, it is often included as part of the consolidation treatment. ${ }^{108}$ However, the addition of L-asparaginase to vincristine and prednisolone in pediatric studies has led to improved CR rates in relapsed ALL patients. ${ }^{109}$ Cyclophosphamide also does not raise the overall $\mathrm{CR}$ rate, but possibly improves the remission quality. Accordingly, standard induction regimens can be labeled as four-drug (vincristine, prednisone, anthracycline, and cyclophosphamide or L-asparaginase) or five-drug (vincristine, prednisone, anthracycline, cyclophosphamide, and L-asparaginase) regimens. No data favor one of these induction regimens over another. A pediatric study showed that the sum of the percentages of three induction drugs (vincristine, L-asparaginase and anthracyclines) delivered were critical in predicting relapse, supporting the concept that the dose intensity of the drugs delivered in induction is important for long-term prognosis. ${ }^{110}$ In an effort to improve upon the outcome, modifications of these standard treatments have been proposed by the addition of known chemotherapy drugs, intensification of chemotherapy doses, 
Table 2 Results of main standard treatment programs for adult ALL

\begin{tabular}{|c|c|c|c|c|c|c|}
\hline $\begin{array}{l}\text { Reference } \\
\text { (trial) }\end{array}$ & Pts & $\begin{array}{l}\text { Age* } \\
\text { (range) }\end{array}$ & CR & DFS & os & $\begin{array}{l}\text { Allogeneic SCT } \\
\text { strategy }\end{array}$ \\
\hline Gaynor et al ${ }^{93}$ & 198 & 35 & $85 \%$ & $46 \%$ & $50 \%$ & $\mathrm{Ph}^{+}$with donor \\
\hline (CALGB 9III) & & $(16-83)$ & & 3 years & 3 years & \\
\hline Petersdorf et a ${ }^{94}$ & 353 & 32 & $62 \%$ & $25 \%$ & $35 \%$ & - \\
\hline (SWOG 84I7/84I9) & & $(15-84)$ & & 5 years & 8 years & \\
\hline Bassan et $\mathrm{al}^{95}$ & 121 & 35 & $84 \%$ & $48 \%$ & $49 \%$ & HR with donor \\
\hline (NILG 08/96) & & $(15-74)$ & & 3 years & 3 years & \\
\hline Takeuchi et al ${ }^{96}$ & 263 & 31 & $78 \%$ & $30 \%$ & $30 \%$ & All pts with donor \\
\hline (JALSG 93) & & $(15-59)$ & & 6 years & 6 years & ( $<40$ years $)$ \\
\hline Hallbook et al ${ }^{97}$ & 153 & 42 & $86 \%$ & $30 \%$ & $28 \%$ & HR with donor \\
\hline (Sweden) & & $(16-82)$ & & 5 years & 5 years & \\
\hline Annino et al ${ }^{98}$ & 767 & 28 & $82 \%$ & $33 \%$ & $27 \%$ & HR with donor \\
\hline (GIMEMA 02/88) & & $(12-60)$ & & 9 years & 9 years & \\
\hline Kantarjian et al ${ }^{99}$ & 288 & NR & $92 \%$ & $38 \%$ & $38 \%$ & $\mathrm{Ph}^{+}$with donor \\
\hline$(\mathrm{MDACC})$ & & $(15-92)$ & & 5 years & 5 years & \\
\hline Labar et al ${ }^{100}$ & 340 & 33 & $74 \%$ & $36 \%$ & $36 \%$ & All pts with donor \\
\hline (EORTC ALL3) & & $(14-79)$ & & 6 years & 6 years & ( $<50$ years $)$ \\
\hline Thomas et al ${ }^{101}$ & 922 & 33 & $84 \%$ & $30 \%$ & $36 \%$ & HR with donor \\
\hline (LALA 94) & & $(15-55)$ & & 5 years & 5 years & \\
\hline Hunault et al ${ }^{102}$ & 198 & 33 & $86 \%$ & NR & $41 \%$ & HR with donor \\
\hline (GOELAL 02) & & $(15-59)$ & & & 6 years & ( $<50$ years $)$ \\
\hline Ribera et al ${ }^{103}$ & 222 & 27 & $82 \%$ & $35 \%$ & $34 \%$ & HR with donor \\
\hline (PETHEMA ALL93) & & $(15-50)$ & & 5 years & 5 years & \\
\hline Gokbuget et al ${ }^{104}$ & 713 & 34 & $89 \%$ & NR & $54 \%$ & HR with donor \\
\hline (GMALL 07) & & $(15-55)$ & & & 5 years & \\
\hline Goldstone et al ${ }^{105}$ & 1646 & NR & $90 \%$ & $N R$ & $39 \%$ & All pts with donor \\
\hline (MRC/ECOG) & & $(15-64)$ & & & 5 years & $(<55$ years $)$ \\
\hline Cornelissen et al ${ }^{106}$ & 433 & $N R$ & NR & NR & $37 \%$ & All pts with donor \\
\hline$(\mathrm{HOVON})$ & & NR & & & 5 years & ( $<55$ years) \\
\hline
\end{tabular}

Note: *Median.

Abbreviations: ALL, acute lymphoblastic leukemia; CALGB, Cancer and Leukemia Group B; CR, complete remission; DFS, disease-free survival; EORTC, European Organisation for Research and Treatment of Cancer; GIMEMA, Gruppo Italiano Malattie Ematologiche dell'Adulto; GMALL, German Multicenter Study Group for Adult ALL; GOELAL, Groupe Ouset-Est des Leucémies Aiguës et Maladies du Sang; HOVON, Dutch-Belgium Cooperative Trial Group for Hematology/Oncology; HR, high-risk; JALSG, Japan Adult Leukemia Study Group; LALA, Leucémies Aiguës Lymphoblastiques de l'Adulte; MDACC, MD Anderson Cancer Center; MRC/ECOG, Medical Research Council/Eastern Cooperative Oncology Group; NLG, Northern Italy Leukemia Group; NR, not reported; OS, overall survival; PETHEMA, Programa Espanol de Tratamiento en Hematologia; Ph+, Philadelphia chromosome-positive; Pts, patients; SCT, stem cell transplantation; SWOG, Southwest Oncology Group.

or incorporation of novel 'targeted' drugs. Although, the addition of other cytotoxic drugs does not increase CR rates substantially, the highest remission rates have been achieved with multidrug induction regimens. Modifications in the chemotherapeutic schedule could include the type and place of corticosteroids, the addition of other drugs during induction, or an intensification of anthracycline doses. Response at a 7-day pretreatment with prednisolone as measured by the reduction of leukemia cells in the peripheral blood is considered as a significant prognostic factor. ${ }^{98}$ Furthermore, a cautious cell reduction phase is recommended for patients with a large leukemic cell burden and/or a high leukocyte count at diagnosis. Dexamethasone has been shown more effective than prednisolone. ${ }^{111,112}$ Its half-life was longer in the cerebrospinal fluid (CSF), ${ }^{113,114}$ but its pharmacokinetics is shown to be related to the concurrent use of other drugs. ${ }^{115}$ High-dose cytosine arabinoside has been introduced in induction chemotherapy in order to increase the quality of remission and to provide efficient prophylaxis of CNS relapse. ${ }^{116}$ This approach does not appear superior to conventional treatment, and it remains uncertain which subgroups may benefit in terms of leukemia-free survival. The exception is the hyper-CVAD regimen, a short-term dose-intense chemotherapy regimen that consists of a combination of fractionated cyclophosphamide, vincristine, and adriamycin and, after hematologic recovery, followed by a second cycle with a noncross-resistant combination of high-dose intravenous methotrexate and cytarabine, which yielded a high CR rate of $91 \% .{ }^{117}$ Methotrexate at a dose of $6 \mathrm{~g} / \mathrm{m}^{2}$ yields cytotoxic levels in the cerebrospinal fluid. Several studies have investigated the efficacy of high-dose methotrexate as induction treatment in combination with other chemotherapeutic agents in adult ALL. ${ }^{118,119}$ Anthracyclines induce more rapid reduction of leukemia cells. The rapidity of CR 
achievement is associated with long-term outcome. The longterm DFS was found to improve when an anthracycline was administered in high doses delivered in a short time. ${ }^{120}$ Early dose intensification of daunorubicin would lead to superior leukemia-free survival. ${ }^{121}$

The antileukemic potential of allogeneic SCT in adult ALL has been confirmed in several studies. A large prospective Medical Research Council (MRC) UKALL XII/ Eastern Cooperative Oncology Group (ECOG) E2993 trial showed a benefit on a donor versus no donor basis for allogeneic sibling transplanted standard-risk ALL with a 5 -year OS of $62 \%$ versus $52 \%$ and a relapse rate of $24 \%$ versus $49 \%$ respectively. ${ }^{105}$ For high-risk ALL patients there was no significant difference concerning OS. However, a meta-analysis of all prospective trials showed a significant benefit for sibling allogeneic SCT in high-risk patients. ${ }^{122}$ In a more recent meta-analysis, allogeneic SCT was superior to autologous SCT or chemotherapy for patients with ALL in first CR. ${ }^{123}$ The survival advantage was of greater statistical significance for patients with standard-risk than for patients with high-risk ALL. This may be explained in part by differences in the definition of high risk versus standard risk. Furthermore, approximately $60 \%$ of adults aged less than 30 years with standard-risk ALL can be cured by chemotherapy, sparing them from the long-term adverse events associated with allogeneic SCT. The recent demonstration of outcome improvements in adolescents and young adults (AYAs) who were treated on pediatric regimens compared to

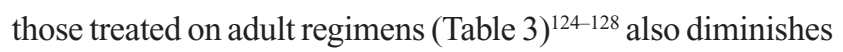
the need to refer this patient group for transplantation.

In the absence of siblings, high-risk ALL adult patients are generally considered for alternative donor SCT. Retrospective studies reported promising results with unrelated donors ${ }^{129-132}$ within several studies, OS and relapse rates similar to those observed with a sibling donor. ${ }^{129,130,132}$

Table 3 Outcome of treatment in adolescents and young adults (AYAs) with ALL

\begin{tabular}{llllll}
\hline Reference & $\begin{array}{l}\text { Type of } \\
\text { trial }\end{array}$ & $\begin{array}{l}\text { Age } \\
\text { (years) }\end{array}$ & Patients & CR & $\begin{array}{l}\text { DFS } \\
\text { (5 years) }\end{array}$ \\
\hline Stock et al $^{124}$ & Pediatric & $|6-2|$ & 196 & $96 \%$ & $64 \%$ \\
& Adult & & 103 & $93 \%$ & $38 \%$ \\
Boissel et al & Pediatric & $15-20$ & 77 & $94 \%$ & $67 \%$ \\
& Adult & & 100 & $83 \%$ & $41 \%$ \\
DeBont et al ${ }^{126}$ & Pediatric & $15-18$ & 47 & $98 \%$ & $69 \%$ \\
& Adult & & 44 & $91 \%$ & $34 \%$ \\
Testi et al'27 & Pediatric & $14-18$ & 150 & $94 \%$ & $80 \%$ \\
& Adult & & 95 & $89 \%$ & $71 \%$ \\
Ramanujachar & Pediatric & $15-17$ & $6 I$ & $98 \%$ & $65 \%$ \\
et al'28 & Adult & & 67 & $94 \%$ & $49 \%$ \\
\hline
\end{tabular}

Abbreviations: CR, Complete remission; DFS, disease-free survival.
TRM was significantly higher with HLA-mismatched donors. ${ }^{131}$ Published studies demonstrated that umbilical cord blood transplantation is an effective treatment alternative for adults with high-risk ALL, lacking a sibling donor or a matched unrelated donor. ${ }^{133,134}$ The limited cell dose of cord blood units can be overcome by the use of double umbilical cord blood units. RIC regimens have been developed over the past decade, with the aim of reducing TRM and making allogeneic SCT feasible in older patients or patients with comorbidities. Small prospective studies in adult ALL patients in first remission demonstrated a 2-year OS at 30\%. ${ }^{135,136}$ Retrospective studies showed globally higher OS rates. ${ }^{137,138}$ An effective GvL effect has been demonstrated. ${ }^{139}$ RIC regimens reduce nonrelapse mortality rate, but with a higher probability of leukemia relapse, inducing similar OS as compared to myeloablative regimens.

Patients who are MDR negative were shown to have a significantly better survival. ${ }^{140}$ Postgraft maintenance remains marginal, but was attempted with some suggested benefit. ${ }^{141}$

\section{Treatment of Philadelphia chromosome-positive ALL}

The Ph chromosome [t(9;22) and/or BCR-ABL ALL] can be detected in a range of $20 \%$ to $40 \%$ of adults with ALL. Historically, chemotherapy regimens induced CRs in about $70 \%$ of the cases, but most patients relapsed and died of the disease. ${ }^{98,101}$ Only the hyperCVAD chemotherapy from the MD Anderson Cancer Center reported higher CR rate (91\%) with better outcome. ${ }^{117}$ Chemotherapy in elderly $\mathrm{Ph}^{+} \mathrm{ALL}$ patients was also associated with a very poor outcome, but (in contrast with younger adults) the presence of $\mathrm{Ph}$ chromosome had no impact on the prognosis because of the overall poor outcome of ALL in the elderly. ${ }^{142}$ Following initial studies showing that use of imatinib mesylate as a single agent in $\mathrm{Ph}^{+}$ ALL yielded potential responses but was unlikely to be sufficient for long-term disease control, the efficacy of imatinib was explored as front-line treatment combined with chemotherapy, either concurrently (simultaneous administration) or sequentially (alternating administration). Results of imatinib-based therapy are given in Table $4 .{ }^{143-152}$ In younger adults, imatinib-based regimens, in which imatinib was given at $400 \mathrm{mg}$ to $800 \mathrm{mg} /$ day, showed significant better results in terms of response as well as of survival when compared to historical control patients treated with chemotherapy alone. ${ }^{143-145,150}$ Transplant candidates had a better chance of receiving allogeneic SCT with imatinib-combined regimen. ${ }^{144}$ Alternating and concurrent imatinib-chemotherapy combinations have been compared. ${ }^{148}$ Efficacy analyses based on BCR-ABL transcript levels showed a clear advantage for 
Table 4 Main studies using imatinib alone or in combination with chemotherapy in newly diagnosed $\mathrm{Ph}^{+} \mathrm{ALL}$

\begin{tabular}{|c|c|c|c|c|c|c|c|}
\hline Reference & Pts & Age & Treatment & $\mathbf{C R}$ & Mol CR & OS & DFS \\
\hline Thomas et $\mathrm{al}^{143}$ & II & $>15$ & Chemotherapy + imatinib & $100 \%$ & $27 \%$ & $75 \%(2 y)$ & \\
\hline Lee et $\mathrm{al}^{145}$ & 29 & $<56$ & Chemotherapy + imatinib & $89 \%$ & & $\begin{array}{l}78 \% \\
(3 y)\end{array}$ & $78 \%(3 y)$ \\
\hline Yanada et al $\left.\right|^{144}$ & 80 & $<65$ & Chemotherapy + imatinib & $96 \%$ & $71 \%$ & $76 \%(1$ y) & $60 \%(1 \mathrm{y})$ \\
\hline $\begin{array}{l}\text { Wassmann } \\
\text { et al }\left.\right|^{148}\end{array}$ & 92 & $<66$ & Chemotherapy + imatinib A or S & $95 \%$ & $\begin{array}{l}19 \% \mathrm{~A} \\
52 \% \mathrm{~S}\end{array}$ & $\begin{array}{l}72 \% A \\
61 \% S \\
(1 \mathrm{y})\end{array}$ & $\begin{array}{l}65 \% A \\
71 \% S \\
(1 \mathrm{y})\end{array}$ \\
\hline Delannoy et al ${ }^{149}$ & 30 & $>54$ & Chemotherapy + imatinib in consolidation & & & $66 \%(1 \mathrm{y})$ & $58 \%(1$ y) \\
\hline $\begin{array}{l}\text { De Labarthe } \\
\text { et al }{ }^{150}\end{array}$ & 45 & $<55$ & $\begin{array}{l}\text { Chemotherapy }+ \text { imatinib in induction } \\
\text { or consolidation }\end{array}$ & $96 \%$ & $62 \%$ & $65 \%(18 \mathrm{~m})$ & $51 \%(18 \mathrm{~m})$ \\
\hline Vignetti et al ${ }^{146}$ & 30 & $>60$ & Imatinib + steroids & $100 \%$ & & $\begin{array}{l}74 \% \\
(12 \mathrm{~m})\end{array}$ & $48 \%(12 \mathrm{~m})$ \\
\hline Ottmann et al $\left.\right|^{147}$ & 28 & $>54$ & Imatinib then imatinib + chemotherapy & $96 \%$ & $43 \%$ & $\begin{array}{l}57 \% \\
(18 \mathrm{~m})\end{array}$ & $\begin{array}{l}29 \% \\
(18 \mathrm{~m})\end{array}$ \\
\hline Fielding et al ${ }^{|5|}$ & $\begin{array}{l}89 \mathrm{~A} \\
64 \mathrm{~S}\end{array}$ & & Chemotherapy + imatinib A or S & $\begin{array}{l}81 \% A \\
91 \% S\end{array}$ & & $\begin{array}{l}23 \% \\
(3 y)\end{array}$ & \\
\hline
\end{tabular}

Abbreviations: Pts, patients; m, months; A, alternating; S, simultaneous; Mol CR, molecular remission; $y$, year.

the simultaneous over the alternating schedule, with $52 \%$ of patients achieving PCR negativity (versus 19\%). Several approaches using imatinib-based induction therapy have been explored for elderly patients. With relatively minimal use of imatinib (600 mg/day for three blocks of 60 days) alternating with chemotherapy, a significant improvement in the 1-year survival was observed compared with historical controls. ${ }^{149}$ Similar results were reported with continuous administration of imatinib (800 mg) only combined with prednisone. ${ }^{146}$ In a randomized study comparing induction therapy with singleagent imatinib with standard induction chemotherapy, ${ }^{147}$ response rate was better with single-agent imatinib ( $96 \%$ versus $50 \%$ ). Achievement of molecular remission was associated with longer DFS. Unfortunately, imatinib resistance developed rapidly and was quickly followed by disease progression. Disease recurrence was related with a high rate of ABL mutations in the tyrosine kinase domain. ${ }^{152}$

Allogeneic SCT from a sibling donor remains the treatment of choice for postremission in younger adults with $\mathrm{Ph}^{+}$ ALL. ${ }^{105}$ RIC is feasible in older patients with reported 3-year OS rates of $50 \% .{ }^{135}$ Matched unrelated donor or umbilical cord blood transplantation is also a feasible approach for patients lacking a sibling donor. ${ }^{153}$ An important and unanswered question concerns whether TKIs should be administered after allogeneic SCT or under what circumstances. Imatinib has been shown to be poorly tolerated after myeloablative allogeneic SCT. ${ }^{154}$ Most patients who started imatinib after the detection of $B C R-A B L$ had a prompt suppression of $B C R-A B L$ in response to the drug. A small study showed a trend toward improved outcome in patients who could receive imatinib in the pre- and posttransplantation period. ${ }^{155}$ Imatinib given after
RIC with fludarabine and 2Gy of TBI was associated with significantly reduced mortality. ${ }^{156}$ Regular and quantitative BCR-ABL monitoring is strictly necessary if an expectant policy is to be followed.

\section{Treatment of Burkitt's lymphoma/leukemia}

Accounting for $1 \%$ to $3 \%$ of all cases of ALL, Burkitt cell ALL is characterized by the morphology of blast cells, the presence of monoclonal surface immunoglobulins, and by chromosomal translocations $[\mathrm{t}(8 ; 14)(\mathrm{q} 24 ; \mathrm{q} 32), \mathrm{t}(2 ; 8)$ $(\mathrm{p} 12 ; \mathrm{q} 24)$ or $\mathrm{t}(8 ; 22)(\mathrm{q} 24 ; \mathrm{q} 11)]$ that lead to rearrangements of the protooncogene c-myc, located at the band 8q24. Burkitt cell ALL prognosis had long been regarded as uniformly poor, because of frequent CNS involvement and early relapses. Conventional ALL treatments combining vincristine, prednisone, an anthracycline, L-asparaginase and intrathecal injections of methotrexate only gave $30 \%$ to $50 \%$ of CR rates, with most patients subsequently exhibiting CNS relapse. Over the past 15 years, survival has improved with the use of aggressive protocols including intensive induction and early CNS disease treatment. Introduction of fractionated high doses of cyclophosphamide (or ifosfamide), intermediate or high-dose methotrexate and cytarabine, and an epidophyllotoxin (VP16 or VM26) in addition to an anthracycline and vincristine yielded improvements in the outcome of the disease. A 1-week prephase (generally combining cyclophosphamide, vincristine and prednisone) was usually started before high-dose chemotherapy in order to reduce the risk of tumor lysis syndrome. Concomitantly, the poor outcome of Burkitt cell ALL patients with CNS involvement led to approaches using intensification of CNS 
therapy combining high-dose methotrexate $\left(5\right.$ to $\left.8 \mathrm{~g} / \mathrm{m}^{2}\right)$ and more intrathecal injections, followed by consolidation with etoposide and high-dose cytarabine, and cranial irradiation. CR rates ranged from $60 \%$ to $100 \%$ and long-term DFS between 50\% and 88\%. ${ }^{157-161}$ Recently, rituximab (anti-CD20) has been combined with Burkitt-tailored chemotherapy. Preliminary results show a high response rate. ${ }^{161}$

\section{Emerging therapy options}

Despite continuous progress in curing ALL, novel approaches need to be incorporated into salvage regimens as well as into front-line therapy for high-risk patients. Measurement of minimal residual disease (MRD) has significantly improved risk stratification and helped guide the intensification of therapy. Efforts at improving drug delivery are ongoing and new formulations of existing chemotherapeutic agents have been proposed. Asparaginase is the best example of improvement of an existing formulation of an active agent. Modified versions of L-asparaginase, such as asparaginase from other sources, pegylated formulations, and asparaginase loaded into erythrocytes have been recently proposed as therapeutic alternatives to native L-asparaginase. Polyethylene glycolconjugated L-asparaginase (PEG-asparaginase) has decreased immunogenicity and a five fold longer half-life, allowing one dose to be substituted for several doses of the native product. ${ }^{162}$ Monoclonal antibodies (MoAbs) against leukemia-associated antigens and novel molecular therapeutics have also been added to certain ALL regimens. Among new formulations of existing chemotherapeutic agents, liposomal cytarabine is a formulation of cytarabine encapsulated into multivesicular lipid-based particles. Cytotoxic levels of cytarabine are maintained for as long as 2 weeks in cerebrospinal fluid after intrathecal administration, compared to less than 24 hours following intrathecal administration of the free cytarabine. ${ }^{163}$ The use of liposomal anthracyclines has been limited to a Phase I liposomal daunomycin study in relapsed patients, and in combination with standard chemotherapy in elderly patients. ${ }^{164}$ The clinical benefit of intensive weekly liposomal vincristine in combination with dexamethasone is also being investigated. ${ }^{165}$

\section{Philadelphia chromosome-negative B cell-lineage ALL}

ALL blast cells express a variety of lineage-specific antigens, which are used for the diagnosis and definition of immunological subtypes. Surface and intracellular antigens may also serve as targets for treatment with MoAbs. MoAbs can be administered in several forms: unconjugated form; conjugated to immunotoxins or chemotherapeutic agents, which are carried to the target cell by the antibody; conjugated to radioactive molecules which deliver radiation selectively to malignant cells; as bispecific antibodies, which may reach additional specificity since they are directed at two target antigens; or as direct effector cells to the malignant target. The activity of antibodies depends on the degree of antigen expression on the cell surface. A prerequisite for $\mathrm{MoAb}$ therapy was generally the presence of the target antigen on at least $30 \%$ of the leukemic blasts. Most experience is available for MoAbs directed against B lineage cells such as anti-CD20, anti-CD19 and anti-CD22. The anti-CD20 MoAbs rituximab added to HyperCVAD regimen has been shown to improve survival of patients with CD20+ ALL. ${ }^{166}$ The 3-year OS was 75\% in the rituximab arm compared with $47 \%$ in the control arm. Rituximab is most commonly administered as a $375 \mathrm{mg} / \mathrm{m}^{2}$ weekly infusion for 4 to 6 weeks, although alternative schedules have been explored. A fully human anti-CD20 MoAb, ofatumumab, has demonstrated a higher binding affinity and stronger complement-dependentcytotoxicity in comparison to rituximab. ${ }^{167}$ Epratuzumab (anti-CD22) and its combination with rituximab are currently being evaluated. Blinatumomab, a bispecific anti-CD3 and anti-CD19 monoclonal antibody, is highly effective at time of molecular relapse ${ }^{168}$ and will be evaluated in first-line therapy. Experience with the humanized anti-CD52, alemtuzumab, in ALL has been anecdotal and consist mostly of reduction of blasts, prolonged pancytopenia with increased risk of opportunistic infections. ${ }^{169}$

Clofarabine, an adenosine analog, has demonstrated significant single-agent activity in heavily pretreated patients with ALL. Responses were observed in patients with either B-lineage ALL or T-lineage ALL. ${ }^{170}$ Because clofarabine inhibits both DNA synthesis and repair, several trials are exploring the benefits of combining clofarabine with DNA damaging agents, such as cyclophosphamide or etoposide. ${ }^{171,172}$ Clofarabine has also been administered in combination with cytarabine, based on the ability of clofarabine to potentiate cytarabine triphosphate accumulation in leukemic blasts. ${ }^{173}$ Other potential new agents are forodesine, FLT3 inhibitors, proteasome inhibitors, and mammalian target of rapamycin mTOR inhibitors.

\section{T cell-lineage ALL}

T-lineage ALL are distributed into different subtypes according to maturation stage: thymic (56\%), early-T (23\%), and mature-T (21\%). A correlation has been reported between maturation stage and outcome with the best outcome for thymic T-cell ALL (OS: 60\% to 70\%) compared to early(33\%) and mature-T phenotypes (22\%). ${ }^{174,175}$ 
Several new options for targeted therapy for T-lineage ALL are forthcoming. Nucleoside analogs represent a large group of agents under investigation in T-cell lineage ALL. The purine analog nelarabine is a water-soluble prodrug of 9- $\beta$-D-arabinofuranosylguanine (ara-G), a deoxyguanosine derivative that is resistant to the clivage by purine nucleoside phosphorylase (PNP). T cells are more sensitive to PNP inhibition than $\mathrm{B}$ cells because of their inherently higher kinase and lower nucleotidase levels, favoring phosphorylation of deoxyguanosine. In an adult trial, 26 patients received nelarabine on an alternate day schedule (days 1, 3, and 5) at $1500 \mathrm{mg} / \mathrm{m}^{2}$ per day, and $31 \%$ of them achieved CR. Nelarabine could soon be integrated in front-line therapy. ${ }^{176}$ Forodesine, a PNP inhibitor, is most effective when administered in a continuous daily schedule and may therefore be useful during maintenance therapy. ${ }^{177}$

Members of the NOTCH family have been recently described to play a critical role in $\mathrm{T}$ cell development and their constitutive activation has been linked to T-cell lineage leukemia. ${ }^{178} \gamma$-secretase, which participates in the release of the NOTCH1 intracellular domain before it translocates to the nucleus, is a potential therapeutic target. Small molecule $\gamma$-secretase inhibitors are being intensively studied. ${ }^{179}$

The NUP214-ABL1 fusion is mainly present in T-lineage ALL expressing HOX11 or HOX11L2. Recently, it appears that imatinib mesylate is potentially efficient in these cases. Purine nucleoside phosphorylase (PNP) is a purinemetabolizing enzyme that catalyzes the phophorolysis of purine nucleosides. The unique sensitivity of T-cells to PNP deficiency is attributed to a relatively high level of kinase and low level of nucleotidase activity. Specific inhibitors of PNP are currently in development.

mTOR is a large polypeptide kinase that acts as a nutrient sensor and regulator of translation. mTOR regulates the translation of a specific subset of mRNA transcripts that encode proteins involved in regulating the $\mathrm{G} 1$ to $\mathrm{S}$ phase transition. Rapamycin and the second generation mTOR inhibitors (temserolimus, everolimus, deforolimus) are able to disrupt the function of mTOR and downstream signaling pathways contributing to cellular proliferation. They form potentially synergistic combinations with doxorubicin and methotrexate. ${ }^{180}$

\section{Philadelphia chromosome-positive ALL}

BCR-ABL has tyrosine kinase activity and participates in intracellular signal transduction pathways. Because mutations that inactivate the kinase function result in a transformation-defective protein, it was predicted that small molecular inhibitors of the kinase activity would be highly effective antileukemic agents. New molecular therapeutic strategies with imatinib and other new kinase inhibitors (dasatinib, nilotinib) are being explored in Philadelphia chromosome/BCR-ABL positive ALL.

New strategies, using second generation TKIs, are being developed to overcome resistance to imatinib. Dasatinib, offering simultaneous inhibition of both tyrosine and $S R C$ kinases, may hold more promise in terms of long-term benefit than imatinib, which offers tyrosine kinase inhibition alone. A recent Phase II study combining the hyperCVAD regimen with dasatinib (50 mg BID) for the first 14 days of each cycle showed CR achievement in 93\% of newly diagnosed $\mathrm{Ph}^{+} \mathrm{ALL}$, with molecular remissions observed even after the first cycle. ${ }^{181}$ In a series combining dasatinib (70 mg BID) with only steroids, $\mathrm{CR}$ was achieved in all cases with a very marked clearance of blasts already at day $22 .{ }^{182}$ Nilotinib as monotherapy also appeared to have promising activity and a favorable safety profile. ${ }^{183}$ Its use in combination with chemotherapy is currently tested. Even 20 -fold more potent BCR-ABL inhibition with nilotinib did not induce apoptosis of quiescent $\mathrm{CD} 34^{+}$cells nor did inhibition with a dual SRCABL kinase inhibitor. ${ }^{184}$

The appearance of mutations which are most probably but not exclusively related to resistance led to the avoidance of induction drugs such as anthracyclines or alkylating agents, which can cause mutational resistance; and the preference for methotrexate, cytarabine, and asparaginase. Such a trial in older adult patients led to high $\mathrm{CR}$ rate and improved survival. ${ }^{185}$

Resistance attributable to kinase domain mutations can lead to relapse despite the development of second-generation compounds, including dasatinib and nilotinib. Despite these therapeutic options, the cross-resistant BCR-ABL T315I mutation remains a major clinical challenge. The first evaluations of AP24534 (ponatinib) characterize this drug as a potent multitargeted kinase inhibitor active against T315I and all other BCR-ABL mutants. ${ }^{186-189}$ AP24534 could be the next treatment of choice in hematological malignancies with $\mathrm{Ph}^{+}$ chromosome, particularly $\mathrm{Ph}^{+} \mathrm{ALL}$ known for its frequent occurrence of T315I mutation. However, its potential action on LSCs is still unknown.

\section{Impact on management strategies and patient care Acute myeloid leukemia Better classification of AML}

AML is a heterogeneous disease with large differences in prognosis. Advances in supportive care and better characterization of disease subsets through cytogenetics and molecular 
analysis have led to significant successes in specific subsets of patients such as those with APL and CBF leukemias. In APL, the past two decades have witnessed remarkable advances that transformed this once rapidly fatal disease into the most curable acute leukemia. The introduction of ATRA in the therapy of APL represents the first paradigm of molecularly targeted treatment in human cancer. The more recent introduction of arsenic trioxide has marked an additional milestone in APL treatment. In CBF leukemias, high-dose cytarabine-based regimens now results in cure rates of $60 \%$ to $80 \%{ }^{45,46}$

Although there is consensus on classification and prognostic value of favorable and unfavorable cytogenetics, molecular factors have been identified to refine the risk profile of patients with AML. On the basis of a literature review and expert consensus, European Leukemia Net (ELN) recommendations on diagnosis and management of AML have recently proposed a subdivision of the intermediate risk group. Patients with normal karyotype and either NPM1 or $C E B P \alpha$ genes and absent FLT3-ITD mutation were assigned to the favorable risk group. All other patients with a normal karyotype were classified as intermediate-I. Patients with cytogenetic aberrations not classified as favorable or unfavorable form the intermediate-II group (Table 5). ${ }^{47}$ In younger adults with AML, the ELN classification seems to be the best available framework for prognostic estimations. ${ }^{190}$

\section{Monitoring of MRD}

The current definition of $\mathrm{CR}$ is inadequate and results in a false sense of security for patients and practitioners. Persistent cytogenetic and/or molecular abnormalities after induction chemotherapy are poor independent prognostic indicators. ${ }^{191}$

Table 5 Standardized reporting for correlation of cytogenetic and molecular genetic data in AML with clinical data according to the ELN guideline ${ }^{47}$

\begin{tabular}{|c|c|}
\hline $\begin{array}{l}\text { ELN genetic } \\
\text { risk group }\end{array}$ & Subsets \\
\hline \multirow[t]{4}{*}{ Favorable } & $\mathrm{t}(8 ; 2 I)(\mathrm{q} 22 ; \mathrm{q} 22) ; R U N X I-R U N X I T I$ \\
\hline & $\operatorname{inv}(\mid 6)(p \mid 3 . I q 22)$ or $t(16 ; 16)(p \mid 3 . I ; q 22) ;$ CBFB-MYHII \\
\hline & Mutated NPMI without FLT3-ITD (normal karyotype) \\
\hline & Mutated CEBP $\alpha$ (normal karyotype) \\
\hline \multirow[t]{3}{*}{ Intermediate-I } & Mutated NPMI and FLT3-ITD (normal karyotype) \\
\hline & Wild-type NPMI and FLT3-ITD (normal karyotype) \\
\hline & Wild-type NPMI without FLT3-ITD (normal karyotype) \\
\hline \multirow[t]{3}{*}{ Intermediate-II } & $\mathrm{t}(9 ; 1 \mathrm{I})(\mathrm{p} 22 ; \mathrm{q} 23) ; M L L T 3-M L L$ \\
\hline & Cytogenetic abnormalities not classified as favorable \\
\hline & or adverse \\
\hline \multirow[t]{4}{*}{ Adverse } & $\operatorname{inv}(3)(\mathrm{q} 2 I \mathrm{q} 26.2)$ or $\mathrm{t}(3 ; 3)(\mathrm{q} 2 I ; \mathrm{q} 26.2) ;$ RPN I-EVII \\
\hline & $\mathrm{t}(6 ; 9)(\mathrm{p} 23 ; \mathrm{q} 34) ;$ DEK-NUP2 I 4 \\
\hline & $\mathrm{t}(\mathrm{v} ; \mathrm{I} \mathrm{I})(\mathrm{v} ; \mathrm{q} 23) ; M L L$ rearranged \\
\hline & -5 or del(5q); -7 ; abnl(I7p); complex karyotype \\
\hline
\end{tabular}

Demonstration of MRD by multicolor flow cytometry is also correlated with inferior outcomes. ${ }^{192}$ Postremission assessments of MRD are rapidly becoming part of the standard of care in AML, although the frequency and optimal timing of such assessments are still not clear.

\section{Treatment of elderly patients with AML}

There is reluctance from both patients and physicians to expose older patients to the toxic effects of standard chemotherapy. The benefit associated with intensive chemotherapy remains largely debated, with an extremely poor outcome, even in patients with favorable cytogenetics. Only one third of elderly patients receive intensive induction chemotherapy. ${ }^{193}$ A number of risk scores, in which adjusted hazard ratios from multivariate analyses were used to assign weighted risk points to the identified prognostic factors, have been developed for identifying patients likely to benefit from the traditional induction regimens. ${ }^{194-198}$ Several indices have also been created to measure the influence of comorbidities on the outcome of treatment, and proposed as a counseling and selection tool. Theoretically, the decision regarding the best strategy in elderly patients should be based on the expected outcomes using these risk scores and biological characteristics. Although (in contrast with observations in younger adults) a recent study suggested that a delay in treatment initiation in older patients was feasible and did not affect survival, ${ }^{199}$ do we have time to evaluate patients for these predictors? Sophisticated scoring systems appear now very questionable and not prospectively applicable in daily clinical practice. Models based on risk scores did not take into account the entire population of elderly AML patients, because only patients fit for intensive chemotherapy would benefit from this stratification. Despite the establishment of prognostic indexes leading theoretically to a practical framework for therapeutic decision making, the choice between intensive chemotherapy or new investigational drugs in this patient population remains under the local physician's decision, generally based more on the 'sens clinique' than on mathematical models. ${ }^{200}$ Even if age, white blood cell count and LDH level are immediately available, molecular biology, and even cytogenetics and immunology are not always available at the time of treatment decision. After referring first to the performance status and/or the presence of potential comorbidities for eliminating patients who might receive only supportive care, physician's therapeutic making decision generally takes into account the hematological presentation of AML referring to the proliferative and/or invasive characteristics of leukemia. New therapeutic agents should 
modify our vision of treating older adults. Hypomethylating agents usually proposed for so-called 'unfit' patients yielded interesting results recently in patients usually oriented to intensive chemotherapy (Table 6), with less toxicity, reduced time spent in hospital, and efficacy correlated with reexpression of silenced genes. ${ }^{81,83}$ Achievement of remission did not appear to be a precondition for longer survival, as well as the presence of multiple adverse prognostic factors.

\section{Acute lymphoblastic leukemia Monitoring of MRD}

The optimal type and duration of postremission therapy, the value of further intensifications, and the optimal selection and timing of allogeneic SCT are still debated. Identifying reliable tools for proper patient selection is becoming crucial. The application of new genome-wide screening techniques, such as microarray-based gene expression studies and arraycomparative genomic hybridization (array-CGH) studies, have led to the discovery of new genetic abnormalities for which the exact functional role remains to be investigated. Pharmacogenomics has great potential to improve the use of anti-leukemic agents to reduce toxicity and enhance efficacy by guiding optimal treatment selection, dose individualization, and new drug discovery. ${ }^{201}$ Monitoring of MRD after induction and during consolidation therapy have become powerful predictors of disease recurrence and is used to stratify patients according to risk. ${ }^{202} \mathrm{MRD}$ is evaluable using either multichannel flow cytometry or the real-time quantitative polymerase chain reaction (RQ-PCR). The speed of MRD eradication or the persistence of MRD over time is also predictive. ${ }^{203} \mathrm{MRD}$ monitoring is important in the setting of allogeneic SCT in which high levels before transplant or persistent residual disease after transplant confer a poorer outcome.

Treatment of elderly patients with ALL

Elderly patients have a worse prognosis than younger adults with ALL. Their long-term survival probability is generally under $20 \% .{ }^{204}$ Intensifying chemotherapy reduces the incidence of leukemia resistance, but increases the incidence of death in CR from myelosuppression-related complications. The development of moderate dose intensity consolidation, like those reported by the European Working Group for Adult ALL showing 85\% of CR and a $61 \%$ 1-year survival, are warranted. ${ }^{205}$ Targeted drugs in combination with moderately intensified chemotherapy may also be successful. Cure can rarely be achieved in patients older than 70 years, for which control of leukemic cells and maintenance of an acceptable quality of life are the major goals of management.

\section{Treatment of adolescents and young adults}

Studies of ALL in AYAs demonstrated improved survival for those who were treated by pediatric groups. ${ }^{124-128}$ The 5- to 6-year EFS rate for AYAs treated with pediatric regimens ranges from $65 \%$ to $70 \%$. Reasons explaining this difference include: differences in protocol designs with higher doses of drugs, early and more frequent CNS prophylaxis, and dexamethasone instead of prednisone; biological differences; different practice patterns; and social factors such as support systems and compliance. Sequential measurements of MRD in AYAs with standard-risk ALL treated with pediatric-based schedules will probably provide help in selecting the minority of patients who should be treated with high-risk ALL approaches including allogeneic SCT in first CR. Recently, a pediatric-inspired therapy program for adults has been published showing results comparing favorably with those reported from previous adult programs. ${ }^{206}$ Prospective trials are planned with the possibility of extending the pediatric approach to adults aged up to $40-50$ years. ${ }^{207,208}$

\section{Future research directions}

Leukemia is propagated by a subpopulation of leukemia stem cells (LSCs). ${ }^{209,210}$ From a clinical perspective, it has been demonstrated that LSCs are substantially more resistant to standard forms of chemotherapy than bulk leukemia populations. Thus, elucidating the specific molecular and cellular properties that mediate LSCs survival is an extremely

Table 6 Comparison of patient outcomes after intensive and nonintensive approaches

\begin{tabular}{|c|c|c|c|c|c|c|}
\hline Study & Fenaux et $\mathrm{al}^{83}$ & Blum et $\mathrm{al}^{81}$ & Röllig et al ${ }^{198}$ & & & \\
\hline Patients & 55 & 53 & 38 & 261 & 428 & 182 \\
\hline Risk group & All patients & All patients & Favorable risk & Good intermediate & Adverse intermediate & High risk \\
\hline Treatment & 5-azacytidine & 5-aza-2'-deoxycytidine & Intensive chemotherapy & & & \\
\hline Age (years) & $70(52-80)$ & $74(60-85)$ & $67(6 I-87)$ & & & \\
\hline CR & $18 \%$ & $47 \%$ & $50 \%$ & & & \\
\hline Median OS & 24.5 months & 12.6 months & 9.I months & & & \\
\hline 2-year OS & $50 \%$ & $\approx 24 \%$ & $\approx 44 \%$ & $\approx 37 \%$ & $\approx 16 \%$ & $\approx 6 \%$ \\
\hline
\end{tabular}

Abbreviations: OS, overall survival; CR, complete response. 
important step toward therapeutic success in leukemia. Novel therapies should target both leukemic cells and cells in their surrounding microenvironment. The therapeutic strategies designed to target LSCs within their surrounding microenvironment include adhesion molecule and cytokine antagonists as well as inhibitors of intracellular prosurvival and self-renewal pathways. Upregulation of the prosurvival Bcl-2 and Mcl-1 pathways is a frequent characteristic in leukemic cells in contact with the microenvironment. This could be targeted by drugs such as BH3 mimetics (Bcl-2, ABT-737) or kinase/Cdk inhibitors (Mcl-1, MEK inhibitors). Disruption of migratory and adhesion signals represents an attractive strategy of blocking LSC homing and/or sensitizing leukemic cells to chemotherapy. Targeting CXCR4 has been shown to be efficacious through recruitment of leukemic cells out of their protective microenvironment. ${ }^{211,212}$ The use of neutralizing VLA-4 antibody and inhibitors of VLA-4/VCAM-1 interactions are currently explored in leukemias. ${ }^{213}$ Specific antibodies against CD44, CD123, and CD47 have been reported to reduce the growth of LSCs in different models. ${ }^{214-216}$ Targeting angiogenesis has also been developed for influencing the relationship between LSCs and their microenvironment. The anti-VEGF monoclonal antibody bevacizumab combined with chemotherapy has been demonstrated to improve overall response in a Phase II study. ${ }^{86}$ These approaches may selectively eradicate LSCs without adversely affecting normal stem cells. ${ }^{217}$

\section{Conclusion}

Long-term survival for adult leukemias have improved largely through more intensive use of conventional cytotoxic agents and the development of new conditioning regimens and procedures for transplantation evaluated in the context of large, randomized clinical trials. Clinical factors, genetic features, and initial response to therapy are used in concert to define risk-adapted treatment for all patients. Major recent breakthroughs in therapies have been furthered by important laboratory discoveries. Advances in genomics have also led to opportunities for the application of novel targeted treatments. Several subsets of AML have benefited from recent discoveries. In CBF leukemias, high-dose cytarabine-based regimens have significantly improved outcomes. Molecular studies have also identified patients for whom resistance may be circumvented through the addition of tyrosine kinase inhibitors targeting mutated $c$-Kit. In APL, non chemotherapy strategies using ATRA and arsenic trioxide are currently in development. Several molecular aberrations have been described and have important prognostic implications in cytologically normal AML, yielding to a risk-adapted therapeutic strategy. In ALL, combining chemotherapy with targeted therapies has significantly increased the survival rates in $\mathrm{Ph}^{+} \mathrm{ALL}$ and in Burkitt lymphoma/leukemia, and rituximab has shown a benefit in the subset of CD20+ B-lineage ALL. Improvements in preparative regimens and supportive care measures have also facilitated the expanded application of allogeneic SCT. Future treatment directions aim to improve therapeutic targeting of LSCs. In this setting, new regimens must take into consideration the quiescent cell cycle status of LSCs and therapies must either be capable of killing quiescent cells or activating LSCs cell cycle. Other therapeutic approaches must target cell properties that are most consistently aberrant in LSCs.

\section{Disclosure}

The author reports no conflicts of interest in this work.

\section{References}

1. Bennett JM, Catovsky D, Daniel MT, et al. The morphological classification of acute lymphoblastic leukaemia: Concordance among observers and clinical correlations. Br J Haematol. 1981;47:553-561.

2. Harris NL, Jaffe ES, Diebold J, et al. The World Health Organization classification of neoplasms of the hematopoietic and lymphoid tissues: Report of the Clinical Advisory Committee meeting - Airlie House, Virginia, November 1997. Hematol J. 1997;1:53-66.

3. Slovak M, Kopecky K, Cassileth PA, et al. Karyotypic analysis predicts outcome of preremission and postremission therapy in adult acute myeloid leukemia: A Southwest Oncology Group/Eastern Cooperative Oncology Group Study. Blood. 2000;96:4075-4083.

4. Grimwade D, Walker H, Oliver F, et al. The importance of diagnostic cytogenetics on outcome in AML: Analysis of 1,612 patients entered into the MRC AML 10 Trial. Blood. 1998;92:2322-2333.

5. Thomas X, Elhamri M, Raffoux E, et al. Comparison of high-dose cytarabine and timed-sequential chemotherapy as consolidation for younger adults with AML in first remission: the ALFA-9802 study. Blood. 2011;118:1754-62.

6. Gaidzik VI, Schlenk RF, Moschny S, et al. Prognostic impact of WT1 mutations in cytogenetically normal acute myeloid leukemia: a study of the German-Austrian AML Study Group. Blood. 2009;113: 4505-4511.

7. Renneville A, Boissel N, Zurawski V, et al. Wilms tumor 1 gene mutations are associated with a higher risk of recurrence in young adults with acute myeloid leukemia: a study from the Acute Leukemia French Association. Cancer. 2009;115:3719-3727.

8. Baldus CD, Tanner SM, Ruppert AS, et al. BAALC expression predicts clinical outcome of de novo acute myeloid leukemia patients with normal cytogenetics: a Cancer and Leukemia Group B study. Blood. $2003 ; 102: 1613-1618$.

9. Lugthart S, van Drunen E, van Norden Y, et al. High EVII levels predict adverse outcome in acute myeloid leukemia: prevalence of EVI1 overexpression and chromosome 3q26 abnormalities underestimated. Blood. 2008;111:4329-4337.

10. Gari M, Goodeve A, Wilson G, et al. C-kit proto-oncogene exon 8 in-frame deletion plus insertion mutations in acute myeloid leukaemia. Br J Haematol. 1999; 105:894-900.

11. Marcucci G, Baldus CD, Ruppert AS, et al. Overexpression of the ETS-related gene, ERG, predicts a worse outcome in acute myeloid leukemia with normal karyotype: a Cancer and Leukemia Group B study. J Clin Oncol. 2005;23:9234-9242. 
12. Mrozek K, Marcucci G, Paschka P, et al. Clinical relevance of mutations and gene-expression changes in adult acute myeloid leukemia with normal cytogenetics: Are we ready for a prognostically prioritized molecular classification? Blood. 2007;109:431-448.

13. Döhner K, Schlenk RF, Habdank M, et al. Mutant nucleophosmin (NPM1) predicts favorable prognosis in younger adults with acute myeloid leukemia and normal cytogenetics: interaction with other gene mutations. Blood. 2005;106:3740-3746.

14. Schnittger S, Schoch C, Kern W, et al. Nucleophosmin gene mutations are predictors of favorable prognosis in acute myelogenous leukemia with a normal karyotype. Blood. 2005;106:3733-3739.

15. Preudhomme C, Sagot C, Boissel N, et al. Favorable prognostic significance of CEBPA mutations in patients with de novo acute myeloid leukemia: a study from the Acute Leukemia French Association (ALFA). Blood. 2002;100:2717-2723.

16. Fröhling S, Schlenk RF, Stolze I, et al. CEBPA mutations in younger adults with acute myeloid leukemia and normal cytogenetics: prognostic relevance and analysis of cooperating mutations. $J$ Clin Oncol. 2004;22:624-633.

17. Taskesen E, Bullinger L, Corbacioglu A, et al. Prognostic impact, concurrent genetic mutations, and gene expression features of AML with CEBPA mutations in a cohort of 1182 cytogenetically normal AML patients: further evidence for CEBPA double mutant AML as a distinctive disease entity. Blood. 2011;117:2469-2475.

18. Boissel N, Leroy H, Berthon B, et al. Incidence and prognostic impact of c-Kit, FLT3, and Ras gene mutations in core binding factor acute myeloid leukemia (CBF-AML). Leukemia. 2006;20: 965-970.

19. Jemal A, Siegel R, Ward E, et al. Cancer statistics. CA Cancer J Clin 2006;56:106-130.

20. Béné MC, Castoldi G, Knapp W, et al. Proposals for the immunological classification of acute leukemias. European Group for the Immunological Characterization of Leukemias (EGIL). Leukemia. 1995;9:1783-1786.

21. Campana D. Minimal residual disease in acute lymphoblastic leukemia Semin Hematol. 2009;46:100-106.

22. Schnapp LM. Another notch on the belt. Blood. 2009;113:1615-1616.

23. Issa JP. DNA methylation as a therapeutic targetin cancer. Clin Cancer Res. 2007;13:1634-1637.

24. Rai KR, Holland JF, Glidewell OG, et al. Treatment of acute myelocytic leukemia: a study by Cancer and Leukemia Group B. Blood. 1981;58: 1203-1212.

25. Yates J, Glidewell OJ, Wiernik P, et al. Cytosine arabinoside with daunorubicin and adriamycin for therapy of acute myelocytic leukemia: a CALGB study. Blood. 1982;60:454-462.

26. Dillman RO, Davis RB, Green MR, et al. A comparative study of two different doses of cytarabine for acute myeloid leukemia: a phase III trial of Cancer and Leukemia Group B. Blood. 1991;78: 2520-2526.

27. Preisler H, Davis RB, Kirshner J, et al. Comparison of three remission induction regimens and two postinduction strategies for the treatment of acute nonlymphocytic leukemia: a Cancer and Leukemia Group B study. Blood. 1987;69:1441-1449.

28. Bishop JF, Lowenthal PM, Joshua D, et al. Etoposide in acute nonlymphoblastic leukemia. Blood. 1990;75:27-32.

29. Vogler WR, Velez-Garcia E, Weiner RS, et al. A phase III trial comparing idarubicin and daunorubicin in combination with cytarabine in acute myelogenous leukemia: A Southeastern Cancer Study Group study. J Clin Oncol. 1992;10:1103-1111.

30. Wiernik PH, Banks PL, Case DC Jr, et al. Cytarabine plus idarubicin or daunorubicin as induction and consolidation therapy for previously untreated adult patients with acute myeloid leukemia. Blood. 1992;15: 313-319.

31. Hansen OP, Pedersen-Bjergaard J, Ellegaard G, et al. Aclarubicin plus cytosine arabinoside versus daunorubicin plus cytosine arabinoside in previously untreated patients of acute myeloid leukemia: A Danish National phase III trial. Leukemia. 1991;5:510-516.
32. Berman E, Arlin ZA, Gaynor J, et al. Comparative trial of cytarabine and thioguanine in combination with amsacrine or daunorubicin in patients with untreated acute non-lymphocytic leukemia: Results of the L-16M protocol. Leukemia. 1989;3:115-121.

33. Arlin Z, Case DC Jr, Moore J, et al. Randomized multicenter trial of cytosine arabinoside with mitoxantrone or daunorubicin in previously untreated adult patients with acute nonlymphocytic leukemia (ANLL). Leukemia. 1990;4:177-183.

34. Rees JKH, Gray RG, Wheatley K. Dose intensification in acute myeloid leukemia: greater effectiveness at lower cost. Principle report of the Medical Research Council's AML9 study. Br J Haematol. 1996;94:89-98.

35. Weick JK, Kopecky KJ, Appelbaum FR, et al. A randomized investigation of high-dose versus standard-dose cytosine arabinoside with daunorubicin in patients with previously untreated acute myeloid leukemia: a Southwest Oncology Group study. Blood. 1996;88:2841-2851.

36. Bishop JF, Matthews JP, Young GA, et al. A randomized study of high-dose cytarabine in induction in acute myeloid leukemia. Blood. 1996;87:1710-1717.

37. Schiller G, Gajewski J, Nimer S, et al. A randomized study of intermediate versus conventional-dose cytarabine as intensive induction for acute myelogenous leukemia. Br J Haematol. 1992;81:170-177.

38. Woods WG, Kobrinsky N, Buckley JD, et al. Timed-sequential induction therapy improves postremission outcome in acute myeloid leukemia: a report from the Children's Cancer Group. Blood. 1996;87:4979-4989.

39. Loeb DM, Bowers DC, Civin CI, et al. Intensive timed sequential remission induction chemotherapy with high-dose cytarabine for childhood acute myeloid leukemia. Med Pediatr Oncol. 2001;37:365-371.

40. Büchner T, Hiddemann W, Wörmann B, et al. Double induction strategy for acute myeloid leukemia: the effect of high-dose cytarabine with mitoxantrone instead of standard-dose cytarabine with daunorubicin and 6-thioguanine: a randomized trial by the German AML Cooperative Group. Blood. 1999;93:4116-4124.

41. Hiddemann W, Büchner T. Current status and perspectives of therapy for acute myeloid leukemia. Semin Hematol. 2001;38(Suppl 6):3-9.

42. Kern W, Estey EH. High-dose cytarabine arabinoside in the treatment of acute myeloid leukemia: Review of three randomized trials. Cancer. 2006;107:116-124.

43. Mayer RJ, Davis RB, Schiffer CA, et al. Intensive postremission chemotherapy in adults with acute myeloid leukemia: Cancer and Leukemia Group B. N Engl J Med. 1994;331:896-903.

44. Cassileth P, Lynch E, Hines JD, et al. Varying intensity of post-remission therapy in acute myeloid leukemia. Blood. 1992;79:1924-1930.

45. Bloomfield CD, Lawrence D, Byrd JC, et al. Frequency of prolonged remission duration after high-dose cytarabine intensification in acute myeloid leukemia varies by cytogenetic subtype. Cancer Res. 1998;58: 4173-4179.

46. Byrd JC, Dodge RK, Carroll A, et al. Patients with $\mathrm{t}(8 ; 21)(\mathrm{q} 22, \mathrm{q} 22)$ and acute myeloid leukemia have superior failure-free and overall survival when repetitive cycles of high-dose cytarabine are administered. J Clin Oncol. 1999;17:3767-3775.

47. Döhner H, Estey EH, Amadori S, et al. Diagnosis and management of acute myeloid leukemia in adults: Recommendations from an international expert panel, on behalf of the European LeukemiaNet. Blood. 2010;115:453-474.

48. Burnett AK, Goldstone AH, Stevens R, et al. Randomised comparison of addition of autologous bone-marrow transplantation in intensive chemotherapy for acute myeloid leukaemia in first remission: results of MRC AML 10 trial. Lancet. 1998;351:700-708.

49. Cassileth PA, Harrington DP, Appelbaum F, et al. Chemotherapy compared with autologous or allogeneic bone marrow transplantation in the management of acute myeloid leukemia in first remission. $N$ Engl J Med. 1998;339:1649-1656.

50. Harousseau JL, Cahn JY, Pignon P, et al. Comparison of autologous bone marrow transplantation and intensive chemotherapy as postremission therapy in adult acute myeloid leukemia. Blood. 1997;90: 2978-2986. 
51. Zittoun RA, Mandelli F, Willemze R, et al. Autologous or allogeneic bone marrow transplantation compared with intensive chemotherapy in acute myelogenous leukemia. $N$ Engl J Med. 1995;332:217-223.

52. Roboz GJ. Novel approaches to the treatment of acute myeloid leukemia. Hematology. 2011:43-50.

53. Schetelig J, Bornhäuser M, Schmid C, et al. Matched unrelated sibling donors result in comparable survival after allogeneic stem-cell transplantation in elderly patients with acute myeloid leukemia: a report from the Cooperative German Transplant Study Group. J Clin Oncol. 2008:26:5183-91.

54. Büchner T, Berdel WE, Schoch C, et al. Late events in AML. Double induction containing either two courses or one course of high-dose cytarabine plus mitoxantrone and postremission therapy by either autologous stem-cell transplantation or by prolonged maintenance for acute myeloid leukemia. J Clin Oncol. 2006;24:2480-2489.

55. Fenaux P, Le Delay MC, Castaigne S, et al. Effect of all-trans retinoic acid in newly diagnosed acute promyelocytic leukemia. Results of a multicenter randomized trial. Blood. 1993;82:3241-3249.

56. Tallman MS, Andersen JW, Schiffer CA, et al. All-trans retinoic acid in acute promyelocytic leukemia. N Engl J Med. 1997;337:1021-1028.

57. Sanz MA, Martin G, Gonzales M, et al. Risk-adapted treatment of acute promyelocytic leukemia with all-trans retinoic acid and anthracycline monochemotherapy: a multicenter study by the PETHEMA Group. Blood. 2004;103:1237-1243.

58. Sanz MA, Tallman MS, Lo Cocco F. Tricks of the trade for the appropriate management of acute promyelocytic leukemia. Blood. 2005;105: 3019-3025.

59. Sanz MA, Grimwade D, Tallman MS, et al. Management of acute promyelocytic leukemia: recommendations from an expert panel on behalf of the European LeukemiaNet. Blood. 2009;113:1875-1891.

60. Fenaux P, Chastang C, Chevret S, et al. A randomized comparison of all transretinoic acid (ATRA) followed by chemotherapy and ATRA plus chemotherapy and the role of maintenance therapy in newly diagnosed acute promyelocytic leukemia: The European APL Group. Blood. 1999;94:1192-1200.

61. Avvisati G, Petti MC, Lo Cocco F, et al. Induction therapy with idarubicin alone significantly influence event-free survival duration in patients with newly diagnosed hypergranular acute promyelocytic leukemia: Final results of the GIMEMA randomized study LAP 0389 with 7 years of minimal follow up. Blood. 2002;100:3141-3146.

62. Powell BL, Moser B, Stock W, et al. Arsenic trioxide improves eventfree survival and overall survival for adults with acute promyelocytic leukemia: North America Leukemia Intergroup Study C9710. Blood. 2010;116:3751-3757.

63. Soignet SL, Frankel SR, Douer D, et al. United States multicenter study of arsenic trioxide in relapsed acute promyelocytic leukemia. $J$ Clin Oncol. 2001;19:3852-3860.

64. Lazo G, Kantarjian H, Estey E, et al. Use of arsenic trioxide $\left(\mathrm{AS}_{2} \mathrm{O}_{3}\right)$ in the treatment of patients with acute promyelocytic leukemia: The MD Anderson experience. Cancer. 2003;97:2218-2224.

65. Douer D, Tallman MS. Arsenic trioxide: New clinical experience with an old medication in hematological malignancies. J Clin Oncol. 2005;23:2396-2410.

66. Sanz MA, Lo Cocco F. Arsenic trioxide: Its use in the treatment of acute promyelocytic leukemia. Am J Cancer. 2006;5:183-191.

67. Shen ZX, Shi ZZ, Fang J, et al. All-trans retinoic acid $/ \mathrm{As}_{2} \mathrm{O}_{3}$ combination yields a high quality remission and survival in newly diagnosed acute promyelocytic leukemia. Proc Natl Acad Sci U S A. 2004; 101:5328-5335.

68. Hu J, Liu YF, Wu CF, et al. Long-term efficacy and safety of alltrans retinoic acid/arsenic trioxide-based therapy in newly diagnosed acute promyelocytic leukemia. Proc Natl Acad Sci U S A. 2009;106:3342-3347.

69. Sanz MA, Labopin M, Gorin NC, et al. Hematopoietic stem cell transplantation for adults with acute promyelocytic leukemia in the ATRA era: A survey of the European Cooperative Group for Blood and Marrow Transplantation. Bone Marrow Transpl. 2007;39:461-469.
70. Petersdorf S, Kopecky K, Stuart RK, et al. Preliminary results of Southwest Oncology Group Study S0106: An international intergroup phase 3 randomized trial comparing the addition of gemtuzumab ozogamicin to standard induction therapy followed by a second randomization to post-consolidation gemtuzumab ozogamicin versus no additional therapy for previously untreated acute myeloid leukemia [abstract]. Blood. 2009;114:Abstr 790.

71. Burnett AK, Hills RK, Milligan D, et al. Identification of patients with acute myeloblastic leukemia who benefit from the addition of gemtuzumab ozogamicin: Results of the MRC AML 15 trial. J Clin Oncol. 2011;29:369-377.

72. Castaigne S, Pautas C, Terré C, et al. Fractionated doses of gemtuzumab ozogamicin (GO) combined to standard chemotherapy (CT) improve event-free and overall survival in newly-diagnosed de novo AML patients aged 50-60 years old: a prospective randomized phase 3 trial from the Acute Leukemia French Association (ALFA) [abstract]. 53rd Annual Meeting of the American Society of Hematology. 2011.

73. Kantarjian HM, Erba HP, Claxton D, et al. Phase II study of clofarabine monotherapy in previously untreated older adults with acute myeloid leukemia and unfavorable prognostic factors. $J$ Clin Oncol. 2010;28:549-555.

74. Faderl S, Ravandi F, Huang X, et al. A randomized study of clofarabine versus clofarabine plus low-dose cytarabine as front-line therapy for patients aged 60 years and older with acute myeloid leukemia and high-risk myelodysplastic syndrome. Blood. 2008;112: $1638-1645$.

75. Kottaridis PD, Gale RE, Frew ME, et al. The presence of a FLT3 internal tandem duplication in patients with acute myeloid leukemia (AML) adds important prognostic information to cytogenetic risk group and response to the first cycle of chemotherapy: analysis of 854 patients from the United Kingdom Medical Research Council AML 10 and 12 trials. Blood. 2001;98:1752-1759.

76. Stone RM, DeAngelo DJ, Klimek V, et al. Patients with acute myeloid leukemia and an activating mutation in FLT3 respond to a small-molecule FLT3 tyrosine kinase inhibitor, PKC412. Blood. 2005;105:54-60.

77. Ravandi F, Cortes JE, Jones D, et al. Phase I/II study of combination therapy with sorafenib, idarubicin, and cytarabine in younger patients with acute myeloid leukemia. J Clin Oncol. 2010;28:1856-1862.

78. Cortes J, Foran J, Ghirdaladze D, et al. AC220, a potent, selective, second generation FLT3 receptor tyrosine kinase (RTK) inhibitor, in a first-in-human (FIH) phase 1 AML study [abstract]. Blood. 2009;114: Abstr 636

79. Soriano AO, Yang H, Faderl S, et al. Safety and clinical activity of the combination of 5-azacytidine, valproic acid, and all-trans retinoic acid in acute myeloid leukemia and myelodysplastic syndrome. Blood. 2007;110:2302-2308.

80. Cashen AF, Schiller GJ, O’Donnell MR, DiPersio JF. Multicenter, phase II study of decitabine for the first-line treatment of older patients with acute myeloid leukemia. J Clin Oncol. 2010;28:556-561.

81. Blum W, Garzon R, Klisovic RB, et al. Clinical response and miR$29 \mathrm{~b}$ predictive significance in older AML patients treated with a 10-day schedule of decitabine. Proc Natl Acad Sci U S A. 2010;107: 7473-7478.

82. Thomas XG, Dmoszynska A, Wierzbowska A, et al. Results from a randomized phase III trial of decitabine versus supportive care or lowdose cytarabine for the treatment of older patients with newly diagnosed AML [abstract]. J Clin Oncol. 2011;29(Suppl):Abstr 6504.

83. Fenaux P, Mufti GJ, Hellström-Lindberg E, et al. Azacitidine prolongs overall survival compared with conventional care regimens in elderly patients with low bone marrow blast count acute myeloid leukemia. J Clin Oncol. 2010;28:562-569.

84. Giles F, Vey N, DeAngelo D, et al. Phase 3 randomized, placebocontrolled, double-blind study of high-dose continuous infusion cytarabine alone or with laromustine (VNP40101M) in patients with acute myeloid leukemia in first relapse. Blood. 2009;114:4027-4033. 
85. Harousseau JL, Martinelli G, Jedrzejczak WW, et al. A randomized phase 3 study of tipifarnib compared with best supportive care, including hydroxyurea, in the treatment of newly diagnosed acute myeloid leukemia in patients 70 years or older. Blood. 2009;114:1166-1173.

86. Karp JE, Gojo I, Pili R, et al. Targeting vascular endothelial growth factor for relapsed and refractory adult acute myelogenous leukemias: Therapy with sequential 1-beta-d-arabinofuranosylcytosine, mitoxantrone, and bevacizumab. Clin Cancer Res. 2004;10:3577-3585.

87. Löwenberg B, Morgan G, Ossenkoppele GJ, et al. Phase I/II clinical study of Tosedostat, an inhibitor of aminopeptidases, in patients with acute myeloid leukemia and myelodysplasia. J Clin Oncol. 2010;28:4333-4338.

88. Konopleva M, Konoplev S, Hu W, et al. Stromal cells prevent apoptosis of AML cells by up-regulation of anti-apoptotic proteins. Leukemia. 2002;16:1713-1724.

89. Feldman EJ, Lancet JE, Kolitz JE, et al. Firs-in-man study of CPX351: a liposomal carrier containing cytarabine and daunorubicin in a fixed 5:1 molar ratio for the treatment of relapsed and refractory acute myeloid leukaemia. J Clin Oncol. 2011;29:979-985.

90. Walsby EJ, Coles SJ, Knapper S, Burnett AK. Topoisomerase II inhibitor voreloxin causes cell cycle arrest and apoptosis in myeloid leukaemia cells and acts in synergy with cytarabine. Haematologica. 2011;96:393-399.

91. Löwenberg B, van Putten W, Theobald M, et al. Effect of priming with granulocyte colony-stimulating factor on the outcome of chemotherapy for acute myeloid leukemia. N Engl J Med. 2003;349:743-752.

92. Thomas X, Raffoux E, Botton S, et al. Effect of priming with granulocyte-macrophage colony-stimulating factor in younger adults with newly diagnosed acute myeloid leukemia: a trial by the Acute Leukemia French Association (ALFA) Group. Leukemia. 2007;21:453-461.

93. Gaynor J, Chapman D, Little C, et al. A cause-specific hazard rate analysis of prognostic factors among 199 adults with acute lymphoblastic leukemia: The Memorial Hospital experience since 1969. J Clin Oncol. 1988;6:1014-1030.

94. Petersdorf SH, Kopecky KJ, Head DR, et al. Comparison of the L10M consolidation regimen to an alternative regimen including escalating methotrexate/L-asparaginase for adult acute lymphoblastic leukemia: A Southwest Oncology Group Study. Leukemia. 2001;15:208-216.

95. Bassan R, Pogliani E, Casula P, et al. Risk-oriented postremission strategies in adult acute lymphoblastic leukemia: Prospective confirmation of anthracycline activity in standard-risk class and role of hematopoietic stem cell transplants in high-risk groups. Hematol J. 2001;2:117-126.

96. Takeuchi J, Kyo T, Naito K, et al. Induction therapy by frequent administration of doxorubicin with four other drugs, followed by intensive consolidation and maintenance therapy for adult acute lymphoblastic leukemia: The JALSG-ALL93 study. Leukemia. 2002;16:1259-1266.

97. Hallbook H, Simonsson B, Ahlgren T, et al. High-dose cytarabine in upfront therapy for adult patients with acute lymphoblastic leukaemia. Br J Haematol. 2002;118:748-754.

98. Annino L, Vegna ML, Camera A, et al. Treatment of adult acute lymphoblastic leukemia (ALL): long-term follow-up of the GIMEMA ALL 0288 randomized study. Blood. 2002;99:863-871.

99. Kantarjian H, Thomas D, O'Brien S, et al. Long-term follow-up results of hyperfractionated cyclophosphamide, vincristine, doxorubicin, and dexamethasone (Hyper-CVAD), a dose-intensive regimen, in adult acute lymphocytic leukemia. Cancer. 2004;101:2788-2801.

100. Labar B, Suciu S, Zittoun R, et al. Allogeneic stem cell transplantation in acute lymphoblastic leukemia and non-Hodgkin's lymphoma for patients $\leq 50$ years old in first complete remission: Results of the EORTC ALL-3 trial. Haematologica. 2004;89:809-817.

101. Thomas X, Boiron JM, Huguet F, et al. Outcome of treatment in adults with acute lymphoblastic leukemia: analysis of the LALA-94 trial. J Clin Oncol. 2004;22:4075-4086.

102. Hunault M, Harousseau JL, Delain M, et al. Better outcome of adult acute lymphoblastic leukemia after early genoidentical allogeneic bone marrow transplantation (BMT) than after late high-dose therapy and autologous BMT: A GOELAMS trial. Blood. 2004;104:3028-3037.
103. Ribera JM, Oriol A, Bethencourt C, et al. Comparison of intensive chemotherapy, allogeneic or autologous stem cell transplantation as post-remission treatment for adult patients with high-risk acute lymphoblastic leukemia: Results of the PETHEMA ALL-93 trial. Haematologica. 2005;90:1346-1356.

104. Gokbuget N, Arnold R, Bohme A, et al. Improve outcome in high risk and very high risk ALL by risk adapted SCT and in standard risk ALL by intensive chemotherapy in 713 adult ALL patients treated according to the prospective GMALL study 07/2003 [abstract]. Blood. 2007:Abstr 110.

105. Goldstone AH, Richards SM, Lazarus HM, et al. In adults with standard risk acute lymphoblastic leukaemia, the greatest benefit is achieved from a matched sibling allogeneic transplantation in first complete remission, and an autologous transplantation is less effective than conventional consolidation/maintenance chemotherapy in all patients: final results of the International ALL trial (MRC UKALL XII/ECOG E2993). Blood. 2008;111:1827-1833.

106. Cornelissen JJ, van der Holt B, Verhoef GE, et al. Myeloablative allogeneic versus autologous stem cell transplantation in adult patients with acute lymphoblastic leukemia in first remission: A prospective sibling donor versus no-donor comparison. Blood. 2009;113:1375-1382.

107. Gottlieb AJ, Weinberg V, Ellison RR, et al. Efficacy of daunorubicin in the therapy of adult acute lymphocytic leukemia: A prospective randomised trial by the Cancer and Leukemia Group B. Blood. 1984;64:267-274.

108. Nagura E, Kimura K, Yamada K, et al. Nation-wide randomized comparative study of doxrubicin, vincristine and prednisolone combination therapy with and without L-asparaginase for adult acute lymphoblastic leukemia. Cancer Chemother Pharmacol. 1994;33:359-365.

109. Ertel I, Nesbit M, Hammond D, et al. Effective dose of L-asparaginase for induction of remission in previously treated children with acute lymphocytic leukemia: A report from Children's Cancer Study Group. Cancer Res. 1979;39:3893-3896.

110. Gaynor PS, Steinherz PG, Bleyer WA, et al. Association of delivered drug dose and outcome for children with acute lymphoblastic leukemia and unfavorable presenting features. Med Pediatr Oncol. 1991;19: 221-227.

111. Labar B, Suciu S, Willemze R, et al. Dexamethasone compared to prednisolone for adults with acute lymphoblastic leukemia or lymphoblastic lymphoma: final results of the ALL-4 randomized, phase III trial of the EORTC Leukemia Group. Haematologica. 2010;95:1489-1495.

112. Teuffel O, Kuster SP, Hunger SP, et al. Dexamethasone versus prednisone for induction therapy in childhood acute lymphoblastic leukemia: a systematic review and meta-analysis. Leukemia. 2011;25:1232-1238.

113. Jones B, Freeman AI, Shuster JJ, et al. Lower incidence of meningeal leukemia when prednisone is replaced by dexamethasone in the treatment of acute lymphocytic leukemia. Med Pediatr Oncol. 1991;19:269-275.

114. Bostrom BC, Sensel MR, Sather HN, et al. Dexamethasone versus prednisone and daily oral versus weekly intravenous mercaptopurine for patients with standard-risk acute lymphoblastic leukemia: A report from the Children's Cancer Group. Blood. 2003;101:3809-3817.

115. Yang L, Panetta JC, Cai X, et al. Asparaginase may influence dexamethasone pharmacokinetics in acute lymphoblastic leukemia. J Clin Oncol. 2008;26:1932-1939.

116. Willemze R, Zijlmans JM, den Ottolander GJ, et al. High-dose Ara-C for remission induction and consolidation of previously untreated adults with ALL or lymphoblastic lymphoma. Ann Hematol. 1995;70:71-74.

117. Kantarjian HM, O'Brien S, Smith TL, et al. Results of treatment with hyper-CVAD, a dose-intensive regimen, in adult acute lymphocytic leukemia. J Clin Oncol. 2000;18:547-561.

118. Cuttner J, Mick R, Budman DR, et al. Phase III trial of brief intensive treatment of adult acute lymphocytic leukemia comparing daunorubicin and mitoxantrone: a CALGB study. Leukemia. 1991; $5: 425-431$ 
119. Elonen E, Almqvist A, Hänninen A, et al. Intensive treatment of acute lymphocytic leukaemia in adults: ALL86 protocol [abstract]. Haematologica. 1991;76(Suppl 4):133.

120. Bassan R, Lerede T, Rambaldi A, et al. The use of anthracyclines in adult acute lymphoblastic leukemia. Haematologica. 1995;80: 280-291.

121. Todeschini G, Tecchio C, Meneghini V, et al. Estimated 6-year eventfree survival of $55 \%$ in 60 consecutive adult acute lymphoblastic leukemia patients treated with an intense phase II protocol on high induction dose of daunorubicin. Leukemia. 1998;12:144-148.

122. Yanada M, Matsuo K, Suzuki T, et al. Allogeneic hematopoietic stem cell transplantation as part of postremission therapy improves survival for adult patients with high-risk acute lymphoblastic leukemia: a meta analysis. Cancer. 2006;106:2657-2663.

123. Ram R, Gafter-Gvili A, Vidal L, et al. Management of adult patients with acute lymphoblastic leukemia in first complete remission. Systematic review and meta-analysis. Cancer. 2010;116:3447-3457.

124. Stock W, Sather H, Dodge RK, et al. Outcome of adolescents and young adults with ALL: A comparison of Children's Cancer Group (CCG) and Cancer and Leukemia Group B (CALGB) regimens [abstract]. Blood. 2000;96(Supp1 1):467a.

125. Boissel N, Auclerc MF, Lhéritier V, et al. Should adolescents with acute lymphoblastic leukemia be treated as old children or young adults? Comparison of the French FRALLE-93 and LALA-94 trials. J Clin Oncol. 2003;21:774-780.

126. DeBont JM, van der Holt B, Dekker AW, et al. Significant difference in outcome for adolescents with acute lymphoblastic leukemia treated on pediatric vs adult protocols in The Netherlands. Leukemia. 2004;18:2032-2035

127. Testi AM, Valsecchi MG, Conter V, et al. Difference in outcome of adolescents with acute lymphoblastic leukemia (ALL) enrolled in pediatric (AEIOP) and adult (GIMEMA) protocols [abstract]. Blood. 2004;104(Suppl 1):1954a.

128. Ramanujachar R, Richards S, Hann I, et al. Adolescents with acute lymphoblastic leukaemia: Emerging from the shadow of paediatric and adult treatment protocols. Pediatr Blood Cancer. 2006;47:748-756.

129. Kiehl MG, Kraut L, Schwerdtfeger R, et al. Outcome of allogeneic hematopoietic stem-cell transplantation in adult patients with acute lymphoblastic leukemia: no difference in relation compared with unrelated transplant in first complete remission. J Clin Oncol. 2004;22:2816-2825.

130. Tomblyn MB, Arora M, Baker KS, et al. Myeloablative hematopoietic cell transplantation for acute lymphoblastic leukemia: analysis of graft sources and long-term outcome. J Clin Oncol. 2009;27:3634-3641.

131. Marks DL, Forman SJ, Blume KG, et al. Unrelated donor transplants in adults with Philadelphia-negative acute lymphoblastic leukemia in first complete remission. Blood. 2008;112:426-434.

132. Dahlke J, Kroger N, Zabelina T, et al. Comparable results in patients with acute lymphoblastic leukemia after related and unrelated stem cell transplantation. Bone Marrow Transplant. 2006;37:155-163.

133. Laughlin MJ, Eapen M, Rubinstein P, et al. Outcomes after transplantation of cord blood or bone marrow from unrelated donors in adults with leukemia. N Engl J Med. 2004;351:2265-2275.

134. Rocha V, Labopin M, Sanz G, et al. Transplants of umbilical cord blood or bone marrow from unrelated donors in adults with acute leukemia. N Engl J Med. 2004;351:2276-2285.

135. Bachanova V, Verneris MR, DeFor T, et al. Prolonged survival in adults with acute lymphoblastic leukemia after reduced-intensity conditioning with cord blood or sibling donor transplantation. Blood. 2009;113:2902-2905.

136. Hamaki T, Kami M, Kanda Y, et al. Reduced-intensity stem-cell transplantation for adult acute lymphoblastic leukemia: a retrospective study of 33 patients. Bone Marrow Transplant. 2005;35:549-556.

137. Stein AS, Palmer JM, O’Donnell MR, et al. Reduced-intensity conditioning followed by peripheral blood stem cell transplantation for adult patients with high-risk acute lymphoblastic leukemia. Biol Blood Marrow Transplant. 2009;15:1407-1414.
138. Mohty M, Labopin M, Volin L, et al. Reduced-intensity versus conventional myeloablative conditioning allogeneic stem cell transplantation for patients with acute lymphoblastic leukemia: a retrospective study from the European Group for Blood and Marrow Transplantation. Blood. 2010;116:4439-4443.

139. Mohty M, Bay JO, Faucher C, et al. Graft-versus-host disease following allogeneic transplantation from HLA-identical sibling with antithymocyte globulin-based reduced-intensity preparative regimen. Blood. 2003;102:470-476.

140. Giebel S, Stella-Holowiecka B, Krawczyk-Kulis M, et al. Status of minimal residual disease determines outcome of autologous hematopoietic SCT in adult ALL. Bone Marrow Transplant. 2009;45:1095-1101.

141. Bassan R, Lerede T, Di Bona E, et al. Induction-consolidation with an idarubicin-containing regimen, unpurged marrow autograft, and post-graft chemotherapy in adult acute lymphoblastic leukaemia. Br J Haematol. 1999;104:755-762.

142. Houot R, Tavernier E, Le QH, et al. Philadelphia chromosome-positive acute lymphoblastic leukemia in the elderly: prognostic factors and treatment outcome. Hematology. 2004;9:369-376.

143. Thomas DA, Faderl S, Cortes J, et al. Treatment of Philadelphia chromosome-positive acute lymphoblastic leukemia with hyperCVAD and imatinib mesylate. Blood. 2004;103:4396-4407.

144. Yanada M, Takeuchi J, Sugiura I, et al. High complete remission rate and promising outcome by combination of imatinib and chemotherapy for newly diagnosed BCR-ABL-positive acute lymphoblastic leukemia: a phase II study by the Japan Adult Leukemia Study Group. J Clin Oncol. 2006;24:460-466.

145. Lee KH, Lee JH, Choi SJ, et al. Clinical effect of imatinib added to intensive combination chemotherapy for newly diagnosed Philadelphia chromosome-positive acute lymphoblastic leukemia. Leukemia. 2005;19:1509-1516.

146. Vignetti M, Fazi P, Cimino G, et al. Imatinib plus steroids induces complete remissions and prolonged survival in elderly Philadelphia chromosome-positive patients with acute lymphoblastic leukemia without additional chemotherapy: results of the Gruppo Italiano Malattie Ematologiche dell'Adulto (GIMEMA) LAL0201-B protocol. Blood. 2007; 109:3676-3678.

147. Ottmann OG, Wassmann B, Pfeifer H, et al. Imatinib compared with chemotherapy as front-line treatment of elderly patients with Philadelphia chromosome-positive acute lymphoblastic leukemia (Ph+ ALL). Cancer. 2007;109:2068-2076.

148. Wassmann B, Pfeifer H, Goekbuget N, et al. Alternating versus concurrent schedules of imatinib and chemotherapy as front-line therapy for Philadelphia-positive acute lymphoblastic leukemia $\left(\mathrm{Ph}^{+} \mathrm{ALL}\right)$. Blood. 2006;108:1469-1477.

149. Delannoy A, Delabesse E, Lhéritier V, et al. Imatinib and methylprednisolone alternated with chemotherapy improve the outcome of elderly patients with Philadelphia-positive acute lymphoblastic leukemia: results of the GRAALL AFR09 study. Leukemia. 2006;20: 1526-1532.

150. De Labarthe A, Rousselot P, Huguet-Rigal F, et al. Imatinib combined with induction or consolidation chemotherapy in patients with de novo Philadelphia chromosome-positive acute lymphoblastic leukemia: results of the GRAAPH-2003 study. Blood. 2007;109: 1408-1413.

151. Fielding AK, Richards SM, Lazarus HM, et al. Does imatinib change the outcome in Philadelphia chromosome positive acute lymphoblastic leukaemia in adults? Data from the UKALLXII/ECOG2993 study [abstract]. Blood. 2007;110:10a.

152. Pfeifer H, Wassmann B, Pavlova A, et al. Kinase domain mutations of BCR-ABL frequently precede imatinib-based therapy and give rise to relapse in patients with de novo Philadelphia-positive acute lymphoblastic leukemia ( $\mathrm{Ph}^{+}$ALL). Blood. 2007;110:727-734.

153. Onishi Y, Sasaki O, Ichikawa S, et al. Favorable outcome of unrelated cord blood transplantation for Philadelphia chromosomepositive acute lyphoblastic leukemia. Biol Blood Marrow Transplant. 2011;17:1093-1097. 
154. Wassmann B, Pfeifer H, Bethge W, et al. Up-front versus minimal residual disease triggered imatinib after stem cell transplantation for Philadelphia chromosome-positive acute lymphoblastic leukaemia: interim results of a randomized phase III GMALL study. Bone Marrow Transplant. 2009;43:S48.

155. Burke MJ, Trotz B, Luo X, et al. Allo-hematopoietic cell transplantation for Ph chromosome-positive ALL: impact of imatinib on relapse and survival. Bone Marrow Transplant. 2009;43:107-113.

156. Ram R, Storb R, Sandmaier BM, et al. Nonmyeloablative conditioning with allogeneic hematopoietic stem cell transplantation for the treatment of high risk acute lymphoblastic leukemia. Haematologica. 2011;96:1113-1120.

157. Patte C, Philip T, Rodary C, et al. High survival rate in advanced-stage B-cell lymphomas and leukemias without CNS involvement with a short intensive polychemotherapy: Results from the French Pediatric Oncology Society of a randomized trial of 216 children. J Clin Oncol. 1991;9:123-132.

158. Thomas DA, Cortes J, O'Brien S, et al. Hyper-CVAD program in Burkitt's-type adult acute lymphoblastic leukemia. J Clin Oncol. 1999; 17:2461-2470.

159. Pees HW, Radtke H, Schwamborn J, et al. The BFM-protocol for HIV-negative Burkitt's lymphomas and L3 ALL in adult patients: A high chance for cure. Ann Hematol. 1992;65:201-205.

160. Lee EJ, Petroni GR, Schiffer CA, et al. Brief-duration high-intensity chemotherapy for patients with small non-cleaved-cell lymphoma or FAB L3 acute lymphocytic leukemia: Results of Cancer and Leukemia Group B study 9251. J Clin Oncol. 2001;19:4014-4022.

161. Thomas DA, Faderl S, O'Brien S, et al. Chemoimmunotherapy with hyper-CVAD plus rituximab for the treatment of adult Burkitt and Burkitt-type lymphoma or acute lymphoblastic leukemia. Cancer. 2006;106:1569-1589.

162. Avramis VI, Sencer S, Periclou AP, et al. A randomized comparison of native Escherichia coli asparaginase and polyethylene glycol conjugated asparaginase for treatment of children with newly-diagnosed standard-risk acute lymphoblastic leukemia: a Children's Cancer Group study. Blood. 2002;99:1986-1994.

163. Bomgaars L, Geyer JR, Franklin J, et al. Phase I trial of intrathecal liposomal cytarabine in children with neoplastic meningitis. $J$ Clin Oncol. 2004;22:3916-3921.

164. Offidani M, Corvatta L, Malerba L, et al. Comparison of two regimens for the treatment of elderly patients with acute lymphoblastic leukaemia (ALL). Leuk Lymphoma. 2005;46:233-238.

165. Thomas DA, Sarris AH, Cortes J, et al. Phase II study of sphingosomal vincristine in patients with recurrent or refractory adult acute lymphocytic leukemia. Cancer. 2006;106:120-127.

166. Thomas DA, Kantarjian HM, Faderl S, et al. Chemoimmunotherapy with a modified hyper-CVAD and rituximab regimen improves outcome for patients with de novo Philadelphia negative precursor B-cell acute lymphoblastic leukemia (ALL) [abstract]. Blood. 2009;114:344.

167. Teeling JL, French RR, Cragg MS, et al. Characterization of new human CD20 monoclonal antibodies with potent cytolytic activity against non-Hodgkin lymphomas. Blood. 2004;104: 1793-1800

168. Topp MS, Zugmaier G, Goekbuget N, et al. Report of a phase II trial of single-agent $\mathrm{BiTE}^{\circledR}$ antibody blinatumomab in patients with minimal residual disease (MRD) positive B-precursor acute lymphoblastic leukemia (ALL) [abstract]. Blood. 2009;114:346.

169. Tibes R, Keating MJ, Ferrajoli A, et al. Activity of alemtuzumab in patients with CD52-positive acute leukaemia. Cancer. 2006;106: 2645-2651.

170. Jeha S, Gaynon PS, Razzouk BI, et al. Phase II study of clofarabine in pediatric patients with refractory or relapsed acute lymphoblastic leukemia. J Clin Oncol. 2006;24:1917-1923.

171. Karp JE, Ricklis RM, Balakrishman K, et al. A phase 1 clinicallaboratory study of clofarabine followed by cyclophosphamide for adults with refractory acute leukemias. Blood. 2007;110:1762-1769.
172. Hijiya N, Franklin J, Rytting M, et al. A phase I study of clofarabine in combination with cyclophosphamide and etoposide: a new regimen in pediatric patients with refractory or relapsed acute leukaemia [abstract]. ASCO Meeting Abstracts. 2007;25:9529.

173. Cooper T, Ayres M, Nowak B, Gandhi V. Biochemical modulation of cytarabine triphosphate by clofarabine. Cancer Chemother Pharmacol. 2005;55:361-368.

174. Vitale A, Guarini A, Ariola C, et al. Adult T-cell acute lymphoblastic leukemia: Biologic profile at presentation and correlation with response to induction treatment in patients enrolled in the GIMEMA LAL 0496 protocol. Blood. 2006;107:473-479.

175. Marks DI, Paietta EM, Moorman AV, et al. T-cell acute lymphoblastic leukemia in adults: Clinical features, immunophenotype, cytogenetics, and outcome from the large randomized prospective trial UKALL XII/ ECOG 2993. Blood. 2009;114:5136-5145.

176. DeAngelo DJ, Yu D, Johnson JL, et al. Nelarabine induces complete remissions in adults with relapsed or refractory T-lineage acute lymphoblastic leukemia or lymphoblastic lymphoma: Cancer and Leukemia Group B study 19801. Blood. 2007;109:5136-5142.

177. Gandhi V, Kilpatrick JM, Plunkett W, et al. A proof-of-principle pharmacokinetic, pharmacodynamic, and clinical study with purine nucleoside phosphorylase inhibitor immucillin-H (BCX-1777, forodesine). Blood. 2005;106:4253-4260.

178. Weng AP, Ferrando AA, Lee W, et al. Activating mutations of NOTCH1 in human T cell acute lymphoblastic leukaemia. Science. 2004;306:269-271.

179. De KK, Lahortiga I, Mentens N, et al. In vitro validation of gammasecretase inhibitors alone or in combination with other anti-cancer drugs for the treatment of T-cell acute lymphoblastic leukemia. Haematologica. 2008;93:533-542.

180. Teachey DT, Sheen C, Hall J, et al. mTOR inhibitors are synergistic with methotrexate: an effective combination to treat acute lymphoblastic leukemia. Blood. 2008;112:2020-2023.

181. Ravandi F, O'Brien S, Thomas D, et al. First report of phase 2 study of dasatinib with hyper-CVAD for the frontline treatment of patients with Philadelphia chromosome-positive $\left(\mathrm{Ph}^{+}\right)$acute lymphoblastic leukemia. Blood. 2010;116:2070-2077.

182. Foa R, Vitale A, Guarini A, et al. Dasatinib as first line treatment of adult $\mathrm{Ph}^{+}$acute lymphoblastic leukemia (ALL) patients: Final results of the GIMEMA LAL1205 Study [abstract]. Blood. 2008; $112: 119$.

183. Ottmann OG, Larson RA, Kantarjian HM, et al. Nilotinib in patients (pts) with relapsed/refractory Philadelphia chromosome-positive acute lymphoblastic leukemia $\left(\mathrm{Ph}^{+} \mathrm{ALL}\right)$ who are resistant or intolerant to imatinib [abstract]. Blood. 2007;110:828A.

184. Jorgensen HG, Allan EK, Jordanides NE, Mountford JC, Holyoake TL. Nilotinib exerts equipotent antiproliferative effects to imatinib and does not induce apoptosis in CD34 ${ }^{+}$CML cells. Blood. 2007;109:4016-4019.

185. Rousselot P, Cayuela JM, Recher C, et al. Dasatinib (Sprycel ${ }^{\circledR}$ ) and chemotherapy for first-line treatment in elderly patients with de novo Philadelphia positive ALL: Results of the first 22 patients included in the EWALL-Ph-01 trial (on behalf of the European Working Group on Adult ALL (EWALL)) [abstract]. Blood. 2008;112:1004-1005.

186. Huang WS, Metcalf CA, Sundaramoorthi R, et al. Discovery of 3-[2-(imidazol[1,2-b]pyridazin-3-yl)ethynyl]-4-methyl-N-\{4-[(4methylpiperazin-1-yl)methyl]-3-(trifluoromethyl)phenyl $\}$ benzamide (AP24534), a potent, orally active pan-inhibitor of breakpoint cluster region-abelson (BCR-ABL) kinase including the T315I gatekeeper mutant. J Med Chem. 2010;53:4701-4719.

187. O'Hare T, Shakespeare WC, Zhu X, et al. AP24534, a pan-BCRABL inhibitor for chronic myeloid leukemia, potently inhibits the T315I mutant and overcomes mutation-based resistance. Cancer Cell. 2009;16:401-412.

188. Cortes J, Talpaz M, Deininger M, et al. A phase 1 trial of oral AP24534 in patients with refractory chronic myeloid leukemia and other hematologic malignancies: first results of safety and clinical activity against T315I and resistant mutations [abstract]. Blood. 2009;114:264. 
189. Talpaz M, Cortes JE, Deininger M, et al. Phase 1 trial of AP24534 in patients with refractory chronic myeloid leukemia (CML) and hematologic malignancies [abstract]. J Clin Oncol. 2010; 28(Suppl):6511.

190. Röllig C, Bornhäuser M, Thiede C, et al. Long-term prognosis of acute myeloid leukemia according to the new genetic risk classification of the European LeukemiaNet recommendations: Evaluation of the proposed reporting system. J Clin Oncol. 2011;29: $2758-2765$.

191. Chen Y, Cortes J, Estrov Z, et al. Persistence of cytogenetic abnormalities at complete remission after induction in patients with acute myeloid leukemia: prognostic significance and the potential role of allogeneic stem-cell transplantation. J Clin Oncol. 2011;29: 2507-2513.

192. Ossenkoppele GJ, van de Loosdrecht AA, Schuurhuis GJ. Review of the relevance of aberrant antigen expression by flow cytometry in myeloid neoplasms. Br J Haematol. 2011;153:421-436.

193. Menzin J, Lang K, Earle CC, Kerney D, Mallick R. The outcomes and costs of acute myeloid leukemia among the elderly. Arch Intern Med. 2002;162:1597-1603.

194. Kantarjian H, O’Brien S, Cortes J, et al. Results of intensive chemotherapy in 998 patients aged 65 years or older with acute myeloid leukemia or high-risk myelodysplastic syndrome: predictive prognostic models for outcome. Cancer. 2006;106:1090-1098.

195. Wheatley K, Brookes CL, Howman AJ, et al. Prognostic factor analysis of the survival of elderly patients with AML in the MRC AML 11 and LRF AML 14 trials. Br J Haematol. 2009;145:598-605.

196. Malfuson JV, Etienne A, Turlure P, et al. Risk factors and decision criteria for intensive chemotherapy in older patients with acute myeloid leukemia. Haematologica. 2008;93:1806-1813.

197. Plesa C, Le QH, Chelghoum Y, et al. Prognostic index for older adult patients with newly diagnosed acute myeloid leukemia: The Edouard Herriot Hospital experience. Clinical Leukemia. 2008;2: 198-204.

198. Röllig C, Thiede C, Gratmatzki M, et al. A novel prognostic model in elderly patients with acute myeloid leukemia: results of 909 patients entered into the prospective AML96 trial. Blood. 2010;116: 971-978.

199. Sekeres MA, Elson P, Kalaycio ME, et al. Time from diagnosis to treatment initiation predicts survival in younger, but not older, acute myeloid leukemia patients. Blood. 2009;113:28-36.

200. Juliusson G, Antunovic P, Derolf A, et al. Age and acute myeloid leukemia: real world data on decision to treat and outcomes from the Swedish Acute Leukemia registry. Blood. 2009;113: 4179-4187.

201. Evans WE, Relling MV. Moving towards individualized medicine with pharmacogenomics. Nature. 2004;429:464-468.

202. Bruggemann M, RaffT, Flohr T, et al. Clinical significance of minimal residual disease quantification in adult patients with standard-risk acute lymphoblastic leukemia. Blood. 2006;107:1116-1123.
203. Spinelli O, Peruta B, Tosi M, et al. Clearance of minimal residual disease after allogeneic stem cell transplantation and the prediction of the clinical outcome of adult patients with high-risk acute lymphoblastic leukemia. Haematologica. 2007;92:612-618.

204. Larson RA. Acute lymphoblastic leukemia: Older patients and newer drugs. American Society of Hematology. Education Program Book. Hematology. 2005:131-136.

205. Goekbuget N, Leguay T, Hunault M, et al. First European chemotherapy schedule for elderly patients with acute lymphoblastic leukemia: promising remission rate and feasible moderate dose intensity consolidation [abstract]. Blood. 2008;112:118.

206. Huguet F, Leguay T, Raffoux E, et al. Pediatric-inspired therapy in adults with Philadelphia chromosome-negative acute lymphoblastic leukemia: the GRAALL-2003 Study. J Clin Oncol. 2009;27:911-918.

207. DeAngelo DJ, Dahlberg S, Silverman LB, et al. A multicenter phase II study using a dose intensified pediatric regimen in adults with untreated acute lymphoblastic leukemia [abstract]. Blood. 2007;110:587.

208. Haiat S, Vekhoff A, Marzac C, et al. Improved outcome of adult acute lymphoblastic leukemia treated with a pediatric protocol: results of pilot study [abstract]. Blood. 2007;110:2822.

209. Bonnet D, Dick JE. Human acute myeloid leukemia is organized as a hierarchy that originates from a primitive hematopoietic cell. Nature Med. 1997;3:730-737.

210. Lapidot T, Sirard C, Vormoor J, et al. A cell initiating human acute myeloid leukaemia after transplantation into SCID mice. Nature. 1994;367:645-648.

211. Juarez J, Bradstock KF, Gottlieb DJ, et al. Effects of inhibitors of the chemokine receptor CXCR4 on acute lymphoblastic leukemia cells in vitro. Leukemia. 2003;17:1294-1300.

212. Nervi B, Ramirez P, Rettig MP, et al. Chemosensitization of acute myeloid leukemia (AML) following mobilization by the CXCR4 antagonist AMD3100. Blood. 2009;113:6206-6214.

213. Ramirez P, Rettig MP, Uy GL, et al. BIO5192, a small molecule inhibitor of VLA-4, mobilizes hematopoietic stem and progenitor cells. Blood. 2009;114:1340-1343.

214. Jin L, Hope KJ, Zhai Q, et al. Targeting of CD44 eradicates human acute myeloid leukemic stem cells. Nature Med. 2006;12:1167-1174.

215. Jin L, Lee EM, Ramshaw HS, et al. Monoclonal antibody-mediated targeting of CD123, IL-3 receptor alpha chain, eliminates human acute myeloid leukemic stem cells. Cell Stem Cell. 2009;5:31-42.

216. Majeti R, Chao MP, Alizadeh AA, et al. CD47 is an adverse prognostic factor and therapeutic antibody target on human acute myeloid leukemia stem cells. Cell. 2009;138:286-299.

217. Konopleva MY, Jordan CT. Leukemia stem cells and microenvironment: Biology and therapeutic targeting. J Clin Oncol. 2011;29:591-599.

218. Armstrong SA, Look AT. Molecular genetics of acute lymphoblastic leukemia. J Clin Oncol. 2005;23:6306-6315.

219. Pui CH, Williams WE. Treatment of acute lymphoblastic leukemia. N Engl J Med. 2006;354:166-178.
Blood and Lymphatic Cancer: Targets and Therapy

\section{Publish your work in this journal}

Blood and Lymphatic Cancer: Targets and Therapy is an international, peer-reviewed, open access journal focusing on blood and lymphatic cancer research, identification of therapeutic targets and the optimal use of preventative and integrated treatment interventions to achieve improved outcomes, enhanced survival and quality of life for the

\section{Dovepress}

cancer patient. The manuscript management system is completely online and includes a very quick and fair peer-review system. Visit http://www.dovepress.com/testimonials.php to read real quotes from published authors. 